\title{
New Hypercoordinating Organostannanes for the Modular Functionalization of Mono- and Polystannanes: Synthetic and Computational Studies
}

Jeffrey Pau, ${ }^{a}$ Jung-Won Choi, ${ }^{a}$ Kaitlyn Silverthorne ${ }^{a}$, Mokhamed Ranne ${ }^{a}$, R. Stephen Wylie a, Robert A. Gossage ${ }^{\text {a }}$ Alan J. Lough ${ }^{b}$ and Daniel A. Foucher*a

A series of potentially hypercoordinate tin compounds derived from a substitutionally labile stannane was produced to gain access to a library of stannanes and polystannanes for structure/property investigations. Three model triphenylstannanes, containing either a propyloxybiphenyl (11), propylmethoxy (12) or propylthioester (13) group were synthesized in high yields via substitution reactions of the propyl tosylated stannane $\mathbf{4}$. Compounds $\mathbf{1 2}$ and $\mathbf{1 3}$ were converted to the appropriate mono-(14, 15) and dichlorido- $(\mathbf{1 8}, \mathbf{1 9})$ stannanes via sequential chlorinations with $\mathrm{HCl}$. Further transformation of 18 or 19 to the dihydridos $(\mathbf{2 2}, \mathbf{2 3})$ was carried out with the use of an appropriate reducing agent. Structural characterizations by single crystal X-ray diffraction of 12, 14, 18 and 19 were also undertaken and are discussed. Several DFT methods were compared for accuracy in predicting the hypercoordinate geometries of these compounds. The relative energies of hypercoordinate conformers for the propylmethoxystannanes 12, 14, 18, and 22 were determined and the fractional abundance of each conformer in the gas and solution $\left(\mathrm{CHCl}_{3}\right)$ phase was estimated. Relativistic DFT calculations of ${ }^{119} \mathrm{Sn} \mathrm{NMR}$ chemical shifts were carried out for a series of non-hypercoordinate reference compounds and the conformers, allowing the estimation of Boltzmann-averaged chemical shifts of the propylmethoxystannanes. A semi-crystalline homopolymer (25) was isolated from the dehydropolymerization of $\mathbf{2 2}$ using Wilkinson's catalyst. Conversion of the liable tosylated polystannane (24) to a new partially substituted polystannane (28) via nucleophile displacement reactions was achieved. The structures of model stannanes, chlorinated stannanes, hydrido stannanes and polystannanes were confirmed via NMR $\left({ }^{1} \mathrm{H},{ }^{13} \mathrm{C},{ }^{119} \mathrm{Sn}\right)$ spectroscopy, HRMS, and, in the case of the polymers $(\mathbf{2 5}, \mathbf{2 8})$, also by elemental analysis, GPC, DSC and PXRD (25).

a. Department of Chemistry and Biology, Ryerson University, 350 Victoria Street, Toronto, Ontario, Canada M5B 2K3, E-mail: daniel.foucher@ryerson.ca

${ }^{b}$ Department of Chemistry, X-Ray Laboratory, University of Toronto, Toronto, ON, Canada M5H 3H6, E-mail: alough@chem.utoronto.ca

\section{Introduction}

Polystannanes are main group polymers with a conjugated backbone of tin atoms prepared from the reductive coupling of dihalido- or dihydrido- diorganostannane monomers. ${ }^{1,2}$ Sodium (Wurtz) ${ }^{3-5}$ or electrochemical coupling ${ }^{6,7}$ of $\mathrm{X}_{2} \mathrm{SnRR}^{\prime}$ leads directly to the desired materials, while conversion of such materials to diorganostannanes, $\mathrm{H}_{2} \mathrm{SnRR}^{\prime}$ followed by transition metal catalyzed dehydropolymerization ${ }^{8-10}$ affords the target polystannanes. Key to both approaches is access to both homo- and hetero-diorganostannanes. This is traditionally achieved by the Kocheshkov reaction, a solventless redistribution of organo and halogen substituents at tetracoordinated tin centers to afford the required organohalo $\left(\mathrm{R}_{4-n} \mathrm{SnCl}_{n}\right)$ tin species. ${ }^{1}$ Experimentally, alkyl substituents have been more difficult to selectively interchange than aryl ones ( $n$-Bu $<\mathrm{Me}<\mathrm{Ph}<\mathrm{Mes}) .{ }^{1}$ Interestingly, an increase of coordination number at tin from four to six has a notable impact on these redistribution reactions. Utilizing van Koten's N,C,N pincer ligand, ${ }^{11}$ (2,6$\left(\mathrm{Me}_{2} \mathrm{NCH}_{2} \mathrm{C}_{6} \mathrm{H}_{3}\right)^{-}$, Růžička and coworkers reported a partial redistribution at RT of an intramolecularly bound monochlorostannane (Figure 1, 1) in solvent to the dichlorostannane and the triphenylstannane after a 2 week time period. ${ }^{12}$ Nechaev and co-workers later detailed the high yield redistribution reaction of six coordinate $\mathrm{PhSn}\left(\kappa^{2}-\mathrm{O}, \mathrm{N}\right.$ $\left.\mathrm{OCH}_{2} \mathrm{CH}_{2} \mathrm{NMe}_{2}\right)_{2} \mathrm{Cl}$ (Figure 1, 2) with $\mathrm{PhSnCl}_{3}$ to the symmetrical dialkoxydichlorostannane and $\mathrm{Ph}_{2} \mathrm{SnCl}_{2} \mathrm{Species}^{13} \mathrm{In}$ both examples, the presence of hypercoordinating interactions from the tethered donor side chains lead to a "reversed" redistribution of these organotin compounds. 


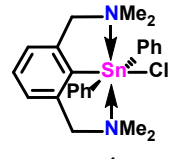

1

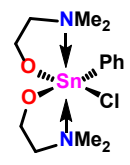

2

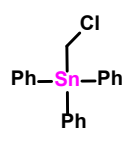

3

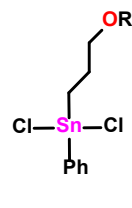

4

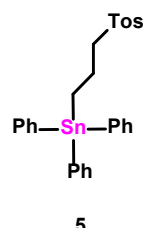

5

Figure 1: Schematic representations of compounds 1-5 $(\mathrm{R}=$ aryl, Tos = tosylated $)$.

Functionalization of stannanes from chlorido or hydrido triorganostannanes has been demonstrated by the teams of Pace and Molloy, respectively. Tandem homogolation of triorganohalostannanes with modified methyl lithium reagents (e.g. $\mathrm{LiCH}_{2} \mathrm{Cl}$ ) yielded $\alpha$-functionalized monohalomethyl stannanes (3) in good yields (> $80 \%$ ). ${ }^{14}$ Molloy reported the preparation of dihalidodiorganostannanes 4 (Figure 1) from an initial hydrostannylation of triphenylstannane with an allyl ether or allyl alcohol substituents, followed by stoichiometric bromination. ${ }^{4}$ Our research ${ }^{15}$ has demonstrated displacement reactions of the tosyl substituent in $\mathbf{5}$ (Figure 1) with 4-hydroxyazobenzene under Williamson ether-like conditions. This approach may be an effective general method to prepare a variety of hypercoordinating stannane monomers for moisture and light stable polystannanes.

Access to a wide variety of functional organic polymers from a single sacrificial macromolecular intermediate has been a successful strategy for the last three decades. ${ }^{16}$ Post-polymerization modification of an intermediate using comparatively mild transformations enables the preparation of polymers that are otherwise hard to access, or sensitive to the polymerization conditions. Additionally, new polymers derived from a single, high yielding, low-cost macromolecular intermediate provides an opportunity to probe structure-property relationships between materials built from a common modular structural platform.

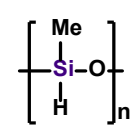

6

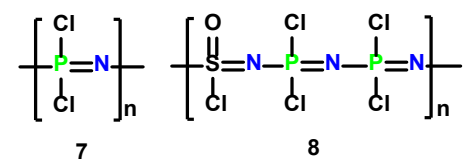

7

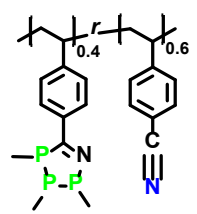

10

Figure 2: Select inorganic and organometallic polymers.

Post-polymerization of main group and organometallic polymers is relatively unexplored with a few notable exceptions. Modification of poly(methylhydrosiloxanes), 6 (Figure 2), with vinylsiloxanes via transition metal-catalyzed hydrosilylation ${ }^{17}$ and the nucleophilic substitution of the halo substituents of thermally ring-opened hexachloropolyphosphazene $^{18}(\mathbf{7})$ or the closely related polythionylphosphazene (8) with alkoxy, amino or organo substituents has been established. ${ }^{19}$ In the mid 1990's, Manners and coworkers also demonstrated the tunable nature of thermally or transition metal-catalyzed ring-opened chlorinated sila[1]ferrocenophanes (9a, b) and were able to prepare substituted poly(ferrocenylsilanes) with sp, sp ${ }^{2}$ and sp ${ }^{3}$ moieties. ${ }^{20}$ In 2017, this same group was able to demonstrate an "inorganic click" reaction with the cycloaddition of cyclophosphines to a polymeric styrene nitrile to yield $10 .{ }^{21}$ This approach provides access to a host of tailored polymers bearing inorganic moieties. To gain access to a broader selection of hypercoordinated stannanes and polystannanes, we have carried out a three-part study. First, we have investigated the substitution chemistry of a model tosylstannane with three nucleophiles, preparing a library of small molecules using reactions potentially extensible to post-polymerization modifications. Second, we have estimated the extent of hypercoordination in solution for a subset of these small molecules using DFT calculations of geometries and ${ }^{119} \mathrm{Sn}$ NMR chemical shifts, with comparison to experimental values. Finally, we disclose our first efforts to prepare tunable hypercoordinated polystannanes by post-polymerization modification of a previously known tosyl-containing polystannane. ${ }^{17}$ Functionally similar polymeric materials were also prepared by dehydrocoupling, where appropriate, for comparison. 


\section{Results and Discussion}

\section{Preparation of Model Stannanes}

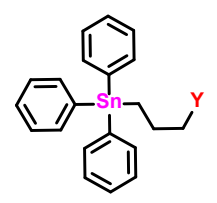

4: $\mathrm{Y}=$ Tosyl

11: $\mathrm{Y}=\mathrm{C}_{6} \mathrm{H}_{5} \mathrm{C}_{6} \mathrm{H}_{4} \mathrm{O}$ -

12: $\mathrm{Y}=\mathrm{MeO}$ -

13: $Y=$ MeCos-

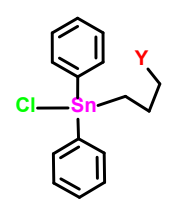

14: $\mathrm{Y}=\mathrm{MeO}$ 15: $Y=$ MeCos-

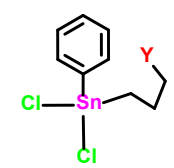

16: $\mathrm{Y}=$ Tosyl17: $\mathrm{Y}=\mathrm{C}_{6} \mathrm{H}_{5} \mathrm{C}_{6} \mathrm{H}_{4} \mathrm{O}$ -

18: $\mathrm{Y}=\mathrm{MeO}$ -

19: $Y=$ MeCos

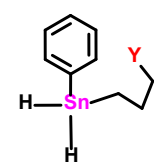

20: $\mathrm{Y}=$ Tosyl-

21: $\mathrm{Y}=\mathrm{C}_{6} \mathrm{H}_{5} \mathrm{C}_{6} \mathrm{H}_{4} \mathrm{O}$ -

22: $Y=M e O-$

23: $Y=$ MeCOS-

Figure 3: Organostannanes evaluated in this study.

The tosylstannane 4, ${ }^{15}$ was prepared in two high yield steps following Yoshida's procedure without the need for column chromatography. ${ }^{23}$ This air- and moisture-stable tosyl intermediate is also tolerant to acidic conditions, while substitutionally reactive under basic conditions. Conditions favourable for substitution at 4 (Figure 3 ) with the methoxy, thioacetyl and biphenyloxy nucleophiles were explored. Williamson ether and Williamson ether-like conditions (Scheme 1) in acetone (Method A) were initially used to prepare compounds $\mathbf{1 1}$ and $\mathbf{1 3}$ in low yields (< 40\%) but was unsuccessful in the case of 12. Higher yields of both 11 and $\mathbf{1 3}$ were obtained (> 75\%) when the reaction was carried out in MeCN (Method B). High purity materials were isolated after extraction (without column chromatography) as determined by NMR spectroscopy $\left({ }^{1} \mathrm{H},{ }^{13} \mathrm{C},{ }^{119} \mathrm{Sn}\right)$, and for $\mathbf{1 1}$ was identical to material previously prepared by hydrostannylation protocols. ${ }^{4}$ Compound $\mathbf{1 3}$ was recovered as a yellow-coloured clear oil, in contrast to solid $\mathbf{1 1 .}$

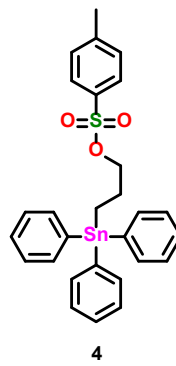

Method A. Nuc, $\mathrm{K}_{2} \mathrm{CO}_{3}, 70^{\circ} \mathrm{C}$, Acetone, 24-72 h

Method B. Nuc, $\mathrm{K}_{2} \mathrm{CO}_{3}, 80^{\circ} \mathrm{C}, \mathrm{MeCN}, 2 \mathrm{~h}$

Method C. NaOMe/MeOH, $80^{\circ} \mathrm{C}, \mathrm{MeCN}, 2 \mathrm{~h}$

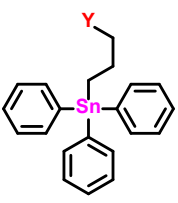

11: $\mathrm{Y}=\mathrm{C}_{6} \mathrm{H}_{5} \mathrm{C}_{6} \mathrm{H}_{4} \mathrm{O}$

13: $\mathrm{Y}=\mathrm{CH}_{3}$ COS-

Scheme 1: Reaction scheme for synthesis of model compounds 11-13.

Compound 12 was readily prepared in good yield as a white coloured solid using $\mathrm{NaOMe} / \mathrm{MeOH}$ in $\mathrm{MeCN}$ under mild conditions ( $<2 \mathrm{~h}$ : Method C). As MeCN was also found to be preferable for substitutions of both the model stannanes and the tosyl polystannane, it was used exclusively thereafter. Compound $\mathbf{1 2}$ was recrystallized from DCM/hexanes and its solid-state structure established by X-ray crystallography (Figure 4: top left). This model triphenylstannane assumes a distorted tetrahedral geometry $\left(\tau_{4}=0.52\right)^{24}$ around the $S n$ centre. The $\mathrm{Sn}(1)-\mathrm{O}(1)$ distance of 12 was $3.030(1) \AA$, falling within the van der Waals radii for Sn and O (3.69 $⿱$ ) but exceeding typical Sn-O covalent bond lengths $\left(2.05 \AA\right.$ ). ${ }^{18}$ 


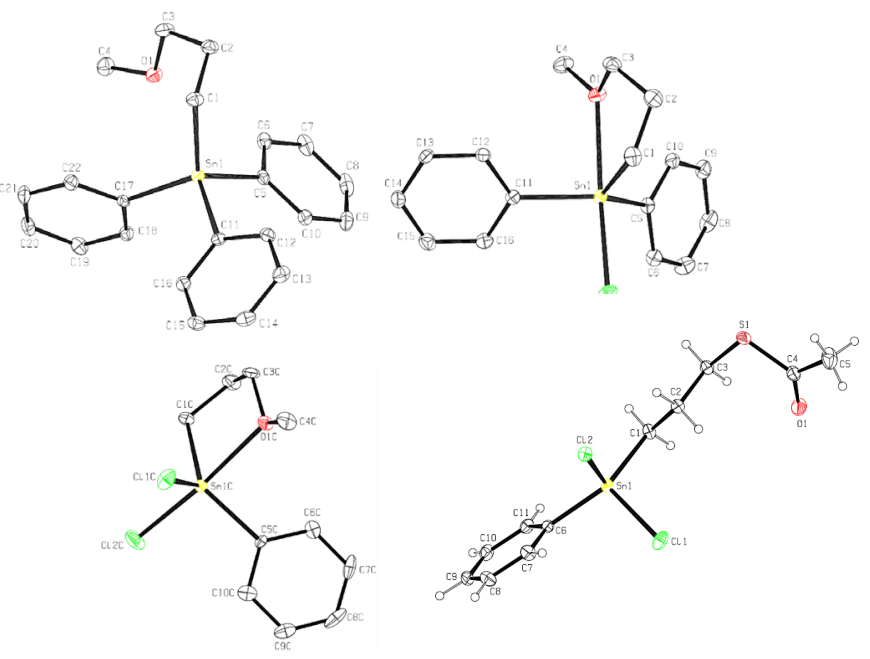

Figure 4: Displacement ellipsoid plots of 12 (top left), 14 (top right), one of the conformers of each 18 (bottom left) and 19 (bottom right). Thermal ellipsoids shown at the $30 \%$ level.

The new model stannanes 22 and 23 were prepared using established protocols. ${ }^{19,20}$ The three step process involved sequential chlorination of the model tristannanes $(\mathbf{1 2}, \mathbf{1 3})$ to monochlorides $(\mathbf{1 4}, \mathbf{1 5})$, then dichlorides $(\mathbf{1 8}, \mathbf{1 9})$ and finally, reduction to the dihydrido $(\mathbf{2 2}, \mathbf{2 3})$ compounds with a mild hydride source (Scheme 2 ).

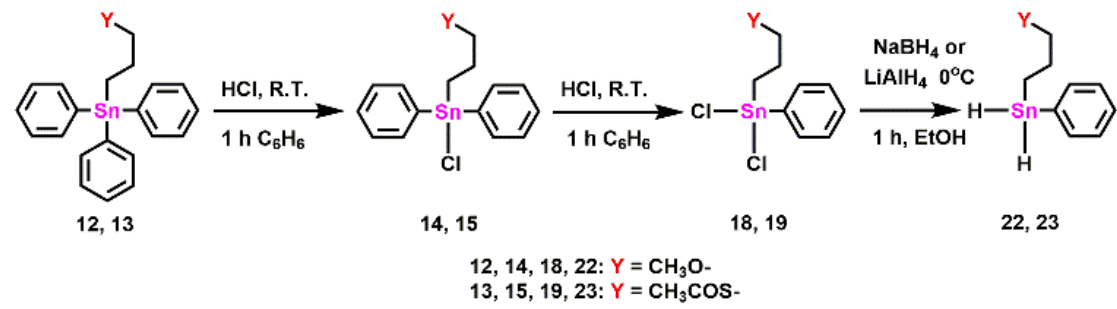

Scheme 2: Preparation of functional stannanes used in this study.

Stannane 14 was obtained through an initial chlorination of 12 (>99\% yield), with further conversion (>95\%) to the dichlorinated stannane $\mathbf{1 8}$ after a second treatment with chlorinating reagent. Both crude chlorinated products were washed with a minimal volume of hexane, recrystallized from a solution of DCM and hexane and recovered as white crystalline solids. Similar transformations were achieved with compounds $\mathbf{1 5}$ and $\mathbf{1 9}$ in good yields and purity with isolation as a yellow-coloured semi-solid and orange-coloured crystals, respectively. The dihydridos $(\mathbf{2 2 , 2 3 )}$ were isolated as white coloured semi-solids and kept at low temperature $\left(-20^{\circ} \mathrm{C}\right)$ and in the absence of light. Large upfield ${ }^{119}$ Sn NMR chemical shifts for these species were observed, consistent with a pseudo-tetrahedral, rather than trigonal bipyramidal geometry around tin. Further structural identification of the chlorinated methoxy-containing compounds 14 and 18 (Figure 4: top right, and bottom left respectively) by single crystal X-ray analysis reveals significant hypercoordination between the methoxy substituent and tin centres, similar to that observed previously by Lebl et al. for the closely related bis(3-methoxypropyl)tin dichloride species (Sn-Oavg $2.557 \AA$ ). ${ }^{21}$ Compound 14 presents approximate trigonal bipyramidal geometry $\left(14: \tau_{5}=0.90\right)^{22}$ and displays a short Sn-O bond distance (2.518(3) $\AA$ ). The structure of 18 contains five independent molecules in the asymmetric unit, all structurally similar, with a geometry between trigonal pyramid and square pyramidal $\left(18: \tau_{5}=0.53_{\mathrm{avg}}\right.$ ). ${ }^{22}$ The $\mathrm{Sn}-\mathrm{O}$ distances are almost identical (averaging $2.445 \pm 0.009 \AA$ A), in line with distances found in other closely related chlorinated stannanes. ${ }^{17}$ By contrast, the thioacetate-containing dichloride 19 (Figure 4, bottom right) reveals a fully extended propyl chain, with evidence of intermolecular hypercoordination. Two molecules of 19 form a dimer with paired Sn thioacetyl oxygen (Sn...O) separation distances of $\approx 2.88 \AA$. The dimers of 19 are weakly associated with other dimers through $\mathrm{Sn} \cdots \mathrm{Cl}$ intermolecular interactions of $\approx 3.36 \AA$, forming a pseudo-octahedral environment at the Sn centres. Similar propyl chain extension was reported previously in the structure of $\mathbf{1 6 . 1 5}$ 


\section{DFT Geometry Optimizations and Structural Comparisons}

In two previous studies, ${ }^{23,24}$ we compared a total of 19 X-ray crystallographic structures of Sn hypercoordinate compounds with those calculated by a selection of computational DFT methods to assess which level of theory provided the best structural predictions. Although comparisons between experimental solid state and calculated gas phase structures are problematic for a variety of reasons, ${ }^{23,25,26}$ there are few other practical options. ${ }^{27}$ In general, adding empirical dispersion to the computational methods significantly improved the accuracy of the calculated structures. The B3PW9128 and PBEO ("PBE1PBE") ${ }^{29}$ functionals supplemented with Grimme's D3 empirical dispersion function and Becke-Johnson damping (GD3BJ) ${ }^{30}$ were the best of ten methods studied; ${ }^{23}$ the M052X ${ }^{31}$ method with Grimme's D3 empirical dispersion (GD3) performed comparably. ${ }^{24}$

In this study, nine crystallographic structures were compared using the three best DFT methods from the previous work as well as the MN1532,33 functional with GD3BJ empirical dispersion (see SI, Table S-1 for details). The four DFT methods used in geometry optimizations gave similar results, with the PBEO-GD3BJ method generally providing the best prediction of solid-state molecular geometries (Table S-1), as previously observed. ${ }^{23,24}$ The M05-2X method also performs well.

\section{DFT Calculation of ${ }^{119}$ Sn NMR Chemical Shifts for Hypercoordinated Stannanes Conformers in Solution}

Extending the computational modelling of these flexible stannane compounds to the calculation of solution-state properties presents three major challenges. First, due to the propyl linkages and hypercoordinate interactions, each of these compounds has several dozen stable conformations. Determining the ${ }^{119} \mathrm{Sn}$ NMR chemical shift for a compound requires calculating the chemical shift for each geometrically optimized conformer, multiplying this by the conformer's Boltzmann-weighted fractional contribution at the measurement temperature and then summing these. A second challenge is due to the solution state model. Implementation of a polarizable continuum model (PCM) for the solvent with quasi-ideal-gas statistical mechanics calculations of thermodynamic properties causes significant overestimation of translational and rotational entropies and thus systematic errors in Gibbs energy estimates. ${ }^{34}$ Finally, it is not known which DFT functionals most accurately predict energies for these conformers in a PCM calculation.

In this study, we adopt some simplifying approximations to make the problem more tractable. First, we focus on the methoxystannane series $\mathbf{1 2}, \mathbf{1 4}, \mathbf{1 8}$, and $\mathbf{2 2}$, because these compounds only have one potentially hypercoordinating substituent (the methoxyl $O$-atom) and are the simplest structurally of the model stannanes in this study (Figure 3 ). Second, we assume that the most stable of the non-hypercoordinating conformers is the one with a fully extended propyl linker in an anti- methoxyl conformation. Third, the calculated solution state Gibbs energies are used for estimating Boltzmann averaged properties for a set of conformers for a given compound. Because the conformers are substantially similar, their translational and rotational entropies are nearly identical and the overestimation cancels out in the Boltzmann averaging. On that basis, we consider the accuracy of the relative Gibbs energies in the solution calculations to be comparable to the gas phase ones. Fourth, we use the PBEO-GD3BJ DFT method, given its good performance in predicting solid state geometries. Each of the compounds has multiple hypercoordinate conformers. For 14, 18, and 22, the Sn substituent trans- to the hypercoordinating $O$-atom can vary $(\mathrm{Ph}$ and $\mathrm{Cl}$ or $\mathrm{H})$ and there are also stable conformers with differing phenyl ring orientations. In hypercoordinate geometries, the methoxy- methyl can adopt an anti- or gauche- conformation with respect to C-2 of the propyl linkage. Only one gauche- conformer is observed because the other would bring the methyl group and Sn center into close proximity. The hypercoordinate and fully extended conformers for each of the methoxystannanes (12, 14, 18, and $\mathbf{2 2}$ ) were determined by geometric optimization without and with solvation (chloroform) and verified with frequency calculations. As expected, hypercoordinate conformers are the lowest energy species, with trans-Cl stabilized relative to trans-Ph in 14 and 18 and trans-Ph stabilized relative to trans- $\mathrm{H}$ in 22. The fractional abundance of each conformer for a given compound was estimated from the Gibbs energy differences. The amounts of the extended non-hypercoordinate conformers are negligible for $\mathbf{1 4}$ and $\mathbf{1 8}$, and minor for $\mathbf{1 2}$ and 22, suggesting that it is reasonable to ignore other higher energy nonhypercoordinate conformers. See SI and Table S-2 for details. The solvation model significantly alters the geometry of the hypercoordinate conformers, notably by reduction of the Sn-O distance (Table S-3). The most stable conformer remains the same for each of the compounds, but the relative energies and fractional abundances of the conformers change (Table S-2). The most stable hypercoordinate conformers for $\mathbf{1 2}$ and $\mathbf{2 2}$ are less stabilized relative to the extended conformers, while those of $\mathbf{1 4}$ and $\mathbf{1 8}$ are more so. Although the distribution of fractional abundances for the various conformers is similar with or without solvation, the differences are significant enough to influence the calculation of the 119Sn NMR chemical shifts. 


\section{DFT ${ }^{119}$ Sn Chemical Shift calculations}

The calculation of ${ }^{119} \mathrm{Sn}$ relative chemical shifts by DFT methods has been extensively studied ${ }^{35}$ (for selected examples see Ref. ${ }^{36-42}$ ). Non-relativistic calculations using the Gauge-Including Atomic Orbitals (GAIO) method and the allelectron IGLO II/III basis set are accurate for Sn compounds lacking other heavy atoms. ${ }^{36,38-40}$ Unfortunately, the IGLO II basis set for Sn does not appear to be in the public domain. Relativistic calculations using the zeroth order regular approximation with spin-orbit coupling (ZORA-SO) also give very good agreement with experimental results, even for Sn compounds with heavy atoms such as $\mathrm{Br}$ or I. ${ }^{37}$

In this work, we apply the ZORA-SO method for ${ }^{119}$ Sn chemical shift calculation to the conformer geometries optimized using the PBEO-GD3BJ level of theory. Using different levels of theory for geometrical optimization and chemical shift calculations is acceptable because the chemical shift is essentially a nuclear property influenced by electronic distributions rather than an intrinsically electronic property. Figure 5 shows the correlation between calculated and experimental ${ }^{119} \mathrm{Sn}$ chemical shifts for a series of non-hypercoordinate reference compounds with structural elements related to the methoxystannane substituents in this study and with a wide range of chemical shifts. The calculated geometries and ${ }^{119}$ Sn NMR chemical shifts are for gas-phase molecules while the experimental chemical shifts were measured in a non-coordinating solvent (usually chloroform). A good linear agreement is obtained with a slope of 1.012, and a correlation coefficient of 0.9966 . Because both experimental and calculated chemical shifts are relative to the chemical shift of $\mathrm{SnMe}_{4}$ defined as $0 \mathrm{ppm}$, the regression must pass through the origin.

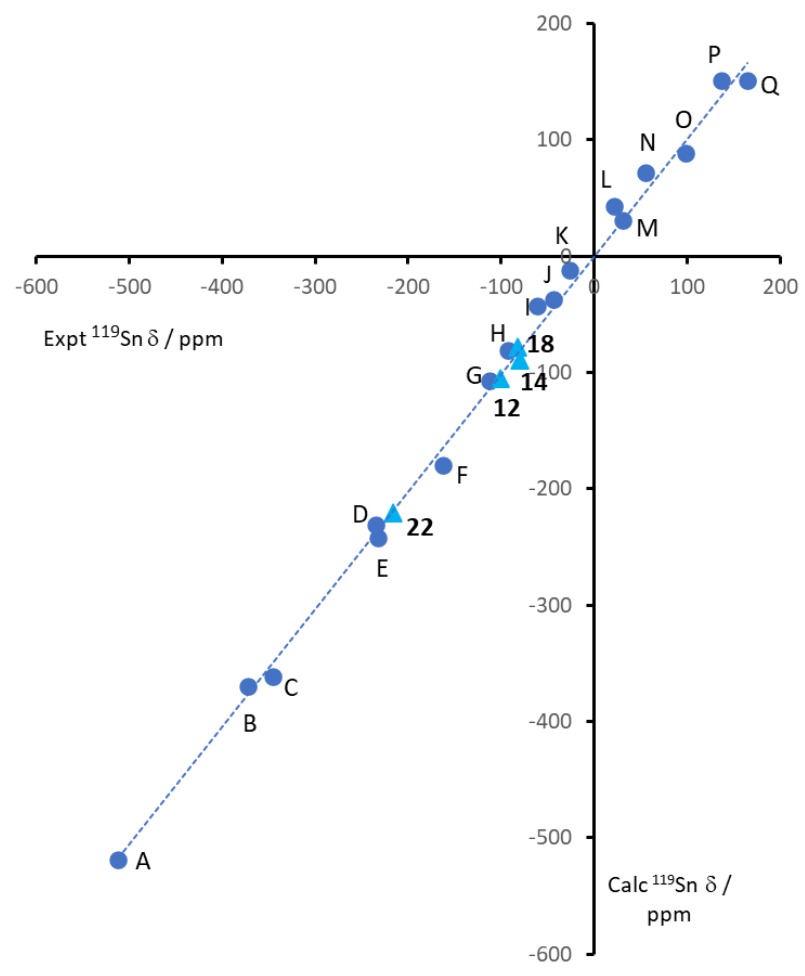

Figure 5. Correlation between calculated and experimental ${ }^{119} \mathrm{Sn}$ chemical shifts. The regression line is for nonhypercoordinate reference tin compounds $A-Q(\bullet)$ : Calc $\delta=m(\operatorname{Exp} \delta), m=1.012, r=0.9966$. Chemical shifts for 12, 14, 18, and $22(\triangle)$ calculated for gas phase conformations with Boltzmann averaging using values in Tables $\mathrm{S}-2$ and $\mathrm{S}-3$ (see SI). Reference compounds: A: $\mathrm{SnH}_{4}, \mathrm{~B}: \mathrm{Sn}\left(\mathrm{CH}_{3}\right) \mathrm{H}_{3}, \mathrm{C}: \mathrm{PhSnH} \mathrm{H}_{3}$ D: $\mathrm{Sn}\left(\mathrm{CH}_{3}\right)_{2} \mathrm{H}_{2}, \mathrm{E}: \mathrm{Ph}_{2} \mathrm{SnH}_{2}, \mathrm{~F}: \mathrm{Ph}{ }_{3} \mathrm{SnH}, \mathrm{G}: \mathrm{Sn}\left(\mathrm{CH}_{3}\right)_{3} \mathrm{H}, \mathrm{H}$ : $\mathrm{Ph}_{3} \mathrm{SnMe}$, I: $\mathrm{PhSnCl}{ }_{3}$, J: $\mathrm{Ph}_{3} \mathrm{SnCl}, \mathrm{K}: \mathrm{Ph}_{2} \mathrm{SnCl}_{2}$, L: Sn $\left(\mathrm{CH}_{3}\right) \mathrm{Cl}_{3}, \mathrm{M}:\left(p-\mathrm{tBu}-\mathrm{C}_{6} \mathrm{H}_{4}-\right)_{2} \mathrm{Sn}\left(\mathrm{CH}_{3}\right) \mathrm{Cl}, \mathrm{N}: \mathrm{PhSn}\left(\mathrm{CH}_{3}\right) \mathrm{Cl}_{2}, \mathrm{O}: \mathrm{PhSn}\left(\mathrm{CH}_{3}\right)_{2} \mathrm{Cl}$, P: $\mathrm{Sn}\left(\mathrm{CH}_{3}\right)_{2} \mathrm{Cl}_{2}$, Q: $\mathrm{Sn}\left(\mathrm{CH}_{3}\right)_{3} \mathrm{Cl}$. Experimental ${ }^{119} \mathrm{Sn}$ chemical shifts: Ref. 43,44: A, B, D, G, L, O-Q; Ref. 40: C, E, F, I-K; Ref. 45: H; Ref. 46: M, N.

Using the same methodology, ${ }^{119}$ Sn NMR chemical shifts were calculated for each of the methoxystannane conformers, as geometrically optimized in both gas and solvent phases (Table S-3). The calculated ${ }^{119} \mathrm{Sn}$ NMR chemical shifts are 
sharply dependent on the Sn-O distances, with extended conformers having shifts close to non-hypercoordinate analogues but hypercoordinate conformers showing significant upfield shifts. Because the optimized geometries of the hypercoordinate conformers in solvent phase typically show shorter Sn-O distances, the calculated chemical shifts tend to be shifted more upfield than for the gas-phase geometries.

Using the estimated fractional abundances of the conformers (Table S-2) and the calculated chemical shifts (Table S-3), Boltzmann-averaged chemical shifts for compounds 12, 14, 18 and 22 were calculated (Figure 5, Table 1). Due to the relatively low Gibbs energy differences for the extended conformers of $\mathbf{1 2}$ and $\mathbf{2 2}$ in the solvent phase compared to the most stable hypercoordinate conformer, the corresponding calculated ${ }^{119} \mathrm{Sn}$ NMR chemical shifts are more approximate; higher energy non-hypercoordinate conformers would also need to be considered in the average. The Boltzmann averaged ${ }^{119}$ Sn NMR chemical shifts for the gas phase geometries agree well with the experimental values, falling essentially on the linear correlation (Figure 5). The values for the compounds calculated with the chloroform solvent model are significantly lower.

On this basis, the PBEO-GD3BJ gas phase model appears to more accurately predict the conformer geometries/relative energies than the solution phase PCM: the condensed phase calculations seemingly overestimate the extent of hypercoordination and systematically underestimate the Sn-O distances. This points to a potential weakness in the "structural benchmarking" approach that has not been previously identified. The PBE0-GD3BJ method was originally selected on the basis of giving the best structural predictions for Sn hypercoordinate compounds in comparison with solid-state X-ray crystallographic structures. This approach may inadvertently factor in the effects of a condensed phase on relatively compressible interactions, such as the $\mathrm{Sn}-\mathrm{O}$ hypercoordination, such that if the gas-phase calculation approximates it, a solution-phase calculation with the same functional will overestimate the strength and underestimate the distance. This suggests that alternative approach(s) are required for accurately modelling hypercoordinate interactions in solution.

Table 1. Experimental and Boltzmann-averaged calculated ${ }^{119} \mathrm{Sn}$ NMR chemical shifts for selected methoxystannanes

\begin{tabular}{|c|c|c|c|}
\hline Compound & $\begin{array}{c}\text { Expt }{ }^{119} \mathrm{Sn} \delta \\
/ \mathbf{p p m}\end{array}$ & $\begin{array}{c}\text { Calc }{ }^{119} \mathrm{Sn} \delta / \mathbf{p p m} \\
\text { (gas phase) }\end{array}$ & $\begin{array}{c}\text { Calc }{ }^{119} \mathrm{Sn} \delta / \mathbf{p p m} \\
\left(\mathrm{CHCl}_{3}\right)\end{array}$ \\
\hline $\mathbf{1 2}$ & $-101.4^{\mathrm{a}}$ & -105.2 & -109.9 \\
\hline $\mathbf{1 4}$ & $-80.0^{\text {a }}$ & -89.7 & -114.7 \\
\hline $\mathbf{1 8}$ & $-82.1^{\text {a }}$ & -78.5 & -103.8 \\
\hline $\mathbf{2 2}$ & $-215.7^{\mathrm{b}}$ & -220.3 & -234.7 \\
\hline
\end{tabular}

\section{Dehydrocoupling Polymerizations}

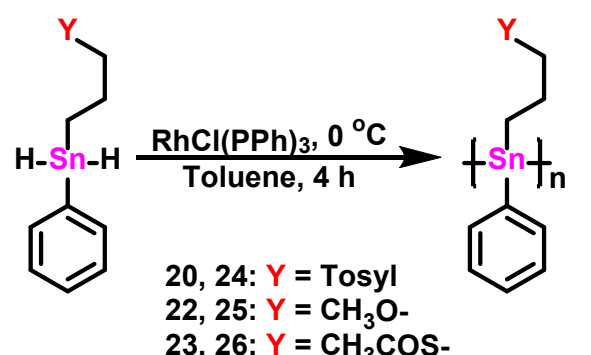

Scheme 3: Synthesis of methoxy, thioacetyl and tosyl homopolymers by dehydropolymerization.

The tosyl-containing polystannane $\mathbf{2 4}$, as previously described, was prepared via a transition metal-catalyzed dehydrocoupling of $\mathbf{2 0}$ in a foil-wrapped Schlenk flask under a $\mathrm{N}_{2}$ atmosphere (Scheme 3). These precautions are to (i) avoid the possibility of light degrading the monomer, (ii) suppress homolytic cleavage of the resulting polystannanes and (iii) prevent the formation of stannoxanes from nucleophilic attack by moisture, respectively. Polymer $\mathbf{2 4}$ was 
purified by precipitation of a THF solution $(3 \mathrm{~mL})$ containing crude 24 into an excess of hexanes $(100 \mathrm{~mL})$ and thereafter recovered as an orange-coloured solid. GPC analysis in THF revealed a molecular weight $\left(\mathrm{M}_{\mathrm{w}}\right)$ of $17 \mathrm{kDa}$ and a $\doteq$ of 1.26 . The tosylated polymer 24 was also characterized by both ${ }^{1} \mathrm{H}$ and ${ }^{119} \mathrm{Sn} N \mathrm{NMR}\left(\mathrm{C}_{6} \mathrm{D}_{6}\right)$ spectroscopy and was in agreement with the reported literature values. ${ }^{17} \mathrm{~A}$ similar dehydrocoupling reaction of $\mathbf{2 2}$ was successfully carried out to yield polymer 25 which was recovered as a yellow coloured powder in moderate yields (64 \%). A molecular weight determination of $\mathbf{2 5}$ after purification proved difficult as the polymer was almost completely insoluble in THF, the solvent required for analysis. Attempts to redissolve purified $\mathbf{2 5}$ in the original reaction solvent also proved futile, and all analyses were thus carried with crude $\mathbf{2 5}$ due to the apparent highly crystalline nature of the resulting polymer. NMR $\left({ }^{119} \mathrm{Sn}\right)$ analysis of the crude polystannane $\mathbf{2 5}$ prior to purification reveal evidence of partial hypercoordination with two nearly equally intense resonances at $\delta=-193$ and $-238 \mathrm{ppm}$ (Figure S53), similar to what was observed for the phenyl propyl hydroxyl stannane polystannane, 27 (Figure 5). ${ }^{17}$ These two signals represent both the "open" and "closed" configurations of the polymer where the methoxy group can potentially interact with a Sn centres.

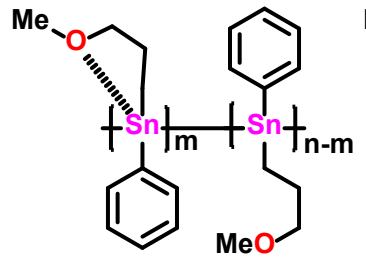

25

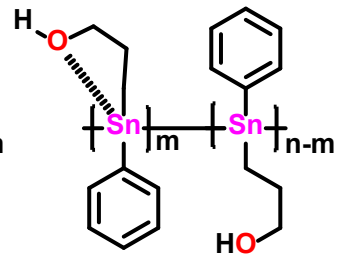

27

Figure 5: Open and closed conformations of stannanes centers in polymers $\mathbf{2 5}$ and $\mathbf{2 7 .}$

After a single purification, the polymer is notably less soluble and displays only a single ${ }^{119} \mathrm{Sn}$ resonance at $-237.9 \mathrm{ppm}$ (Figure S54), suggesting that the polymer likely migrates to a fully "closed" form. DSC analysis of homopolymer $\mathbf{2 5}$ reveals reversible semi-crystalline/highly crystalline character with $\mathrm{T}_{\mathrm{m}}=127^{\circ} \mathrm{C}$, and $\mathrm{T}_{\mathrm{g}}=91{ }^{\circ} \mathrm{C}$ (Figure S63), similar to that for $27\left(T_{m}=110{ }^{\circ} \mathrm{C}\right.$, and $\left.T_{g}=49^{\circ} \mathrm{C}\right)$ as previously reported. ${ }^{17}$ The PXRD diffractogram of 25 (Figure 6) shows five distinct signals. Two of the signals are intense and sharp in nature with $2 \theta$ values of $14.30^{\circ}$ and $17.15^{\circ}$, while the remaining three signals are broad and less intense $\left(2 \theta\right.$ values of $6.35^{\circ}, 18.93^{\circ}$ and $\left.25.90^{\circ}\right)$. These values fall within the same range as other recently reported unsymmetrical polystannanes. ${ }^{15,17}$ The sharp signals in the PXRD diffractogram, in conjunction with the presence of a $T_{m}$ in the DSC thermogram confirm that $\mathbf{2 5}$ is semi- to highly-crystalline in nature.

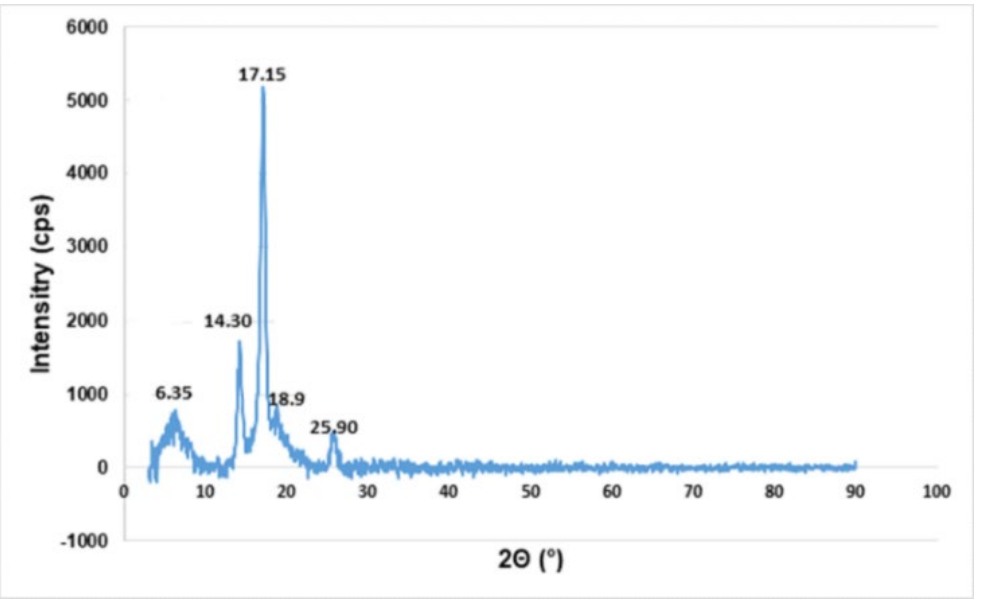

Figure 6: PXRD of homopolystannane $\mathbf{2 5}$ after purification.

Attempts to prepare the thioacetyl homopolymer $\mathbf{2 6}$ from $\mathbf{2 3}$ under similar protocols were unsuccessful owing largely to the extreme sensitivity of the polymer to light, which changed from a light yellow to a darker insoluble brown solid after a minimal exposure to light. Further explorations of this material were therefore abandoned. 
Attempted Macromolecular substitution

Substitution of the tosyl substituent of $\mathbf{2 4}$ for a methoxy functionality was attempted (Scheme 4).

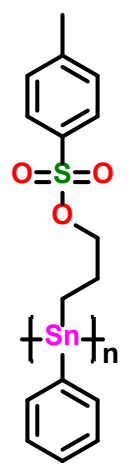

24

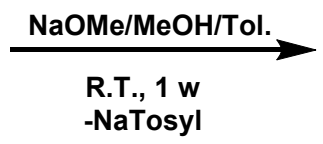

R.T., 1 w

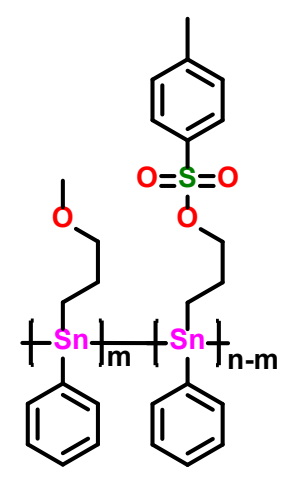

28

Scheme 4: Macromolecular substitution reaction to polystannane 28.

After several attempts (Table S48), the optimized conditions for an $\mathrm{S}_{\mathrm{N}} 2$ type substitution of 24 utilizing a 10:1 mixture of toluene and $\mathrm{MeOH}$ and one equivalent of $\mathrm{NaOMe}$ stirring at RT for 1 week were identified. The crude yellow coloured polymer, 28, was gravity filtered to remove the resulting salts and the volatile components were then removed under reduced pressure. The substituted product, $\mathbf{2 8}$, was further purified by redissolving the crude polymer in a minimum of THF and induced precipitation from this solution by adding it to an excess of cold hexanes. NMR spectroscopic analysis $\left({ }^{1} \mathrm{H},{ }^{119} \mathrm{Sn}\right)$ of the substituted polymer suggests that 28 is $\approx 50 \%$ methoxy substituted. The ${ }^{119} \mathrm{Sn}$ NMR (Figure S56) reveals chemical shift values typically of both the homopolymer $\mathbf{2 5}$ in open and closed conformations, as well as a resonance for the unsubstituted polymer $\mathbf{2 4}$. A GPC analysis of the partially substituted polymer was not performed, as purified $\mathbf{2 8}$ was found to be insufficiently soluble in THF.

\section{Conclusion}

Nucleophilic substitution of a labile model tosylated triphenylstannane $\mathbf{4}$ to either aryloxy, alkyoxy or thioacetate bearing stannanes in good yields was demonstrated. DFT optimization of individual molecules using the PBE0-GD3BJ method generally provided the best predictions of solid-state molecular properties. Modelling of hypercoordinate conformations for the methoxy- series 12, 14, 18, and 22 with PBEO-GD3BJ showed that inclusion of the PCM solvent model predicts significantly shorter $\mathrm{Sn}-\mathrm{O}$ distances than in the gas phase. Relativistic DFT calculations of ${ }^{119} \mathrm{Sn}$ chemical shifts for these conformations with Boltzmann averaging closely approximated experimental values when gas phase geometries and conformer distributions were used but performed poorly with solvent phase ones. The selection of the PBEO-GD3BJ method by "structural benchmarking" gas-phase geometries to solid-state structures may have effectively factored in the impact of a condensed phase on the hypercoordinate interactions, causing the solvation model to overestimate these. A new light and moisture stable semicrystalline polystannane, 25, was prepared by the dehydropolymerization in the presence of Wilkinson's catalyst. Evidence for extensive hypercoordination was detected by ${ }^{119} \mathrm{Sn}$ NMR spectroscopy. Access to the similar, but only partially substituted methoxy stannane, 28, via an $\mathrm{S}_{\mathrm{N}} \mathbf{2}$ reaction involving a tosylated polymeric intermediate $\mathbf{2 4}$ in good yields has also been demonstrated using mild reaction conditions. Despite the sensitivity of the $\mathrm{Sn}-\mathrm{Sn}$ bonds of the liable polystannane, prolonged reaction periods (> 1 week) of tosyl containing polystannane $\mathbf{2 4}$ with a nucleophile in the absence of light can allow access to functionally stable new polystannanes.

\section{Experimental}

\section{General remarks}

${ }^{1} \mathrm{H}$ NMR (400 MHz), ${ }^{13} \mathrm{C}$ NMR (100.6 MHz) and ${ }^{119} \mathrm{Sn}$ NMR (149.2 MHz) spectra were recorded on a Bruker Advance 400 $\mathrm{MHz}$ NMR spectrometer with a BBFO 5-mm direct probe. $\mathrm{A}^{1} \mathrm{H}$ pulse width of $30^{\circ}$ was used, acquiring a spectral window of $8223 \mathrm{~Hz}(20 \mathrm{ppm})$ using a relaxation delay of $1 \mathrm{~s}$, acquisition time $3.98 \mathrm{~s}$, 32k points (16 scans). The ${ }^{1} \mathrm{H} 90^{\circ}$ pulse width 
was $10.4 \mu \mathrm{s}$. A ${ }^{13} \mathrm{C}$ pulse width of $30^{\circ}$ was used, acquiring a spectral window of $24038 \mathrm{~Hz}$ (239 ppm) using a relaxation delay of $2 \mathrm{~s}$, acquisition time $1.36 \mathrm{~s}, 32 \mathrm{k}$ points (4096 scans). The ${ }^{13} \mathrm{C} 90 \%$ pulse width was $8.7 \mu \mathrm{s}$. A ${ }^{119} \mathrm{Sn}$ pulse width of $30 \circ$ was used, $8.75 \mu \mathrm{s}$, acquiring a spectral window of $100000 \mathrm{~Hz}(670 \mathrm{ppm})$ using a relaxation delay of $1 \mathrm{~s}$, acquisition time $0.33 \mathrm{~s}, 32 \mathrm{k}$ points (15360 scans) with inverse gated proton decoupling. All results were analysed on MestReNova LITE 5.2.5 software. Chemical shifts were calculated using the chemical deuterated standards as a reference for ${ }^{1} \mathrm{H}$ and ${ }^{13} \mathrm{C}$. The ${ }^{119} \mathrm{Sn}$ was referenced to $\mathrm{SnMe}_{4}$ as an internal standard. All $J$ coupling values are reported as absolute values. Time-of-flight mass spectrometry analyses were performed at the AIMS Mass Spectrometry Laboratory, University of Toronto using a JMS-T1000LC mass spectrometer (JEOL Inc., Peabody, MA) equipped with a Direct Analysis in Real Time (DART) ionization source (DART-SVP, lonsense Inc., Saugus, MA). The DART source was operated with He gas and the temperature was adjusted in the range $100-400^{\circ} \mathrm{C}$. Isotopic distributions for the observed ionic species were calculated using the Mass Center utility (JEOL) and were in good agreement with the measured mass spectra. Absolute molecular weights of the polymers were determined by GPC using a Viscotek Triple Model 302 Detector system. GPC columns were calibrated versus polystyrene standards (American Polymer Standards). A flow rate of $1.0 \mathrm{~mL} / \mathrm{min}$. was used with ACS grade THF as the eluent. GPC samples were prepared using 3-10 mg of each polymer per mL THF, and filtered using a $0.45 \mu \mathrm{m}$ filter. All samples were run with and without UVA (conc. $\approx 0.001 \mathrm{M}$ ) for comparison. The X-ray diffraction data for compounds 12, 14, 18, and 19 were collected on a Bruker Kappa APEX-DUO diffractometer using monochromated Mo-K ( radiation (Bruker Triumph) and were measured using a combination of ) scans and $\rceil$ scans. The data were processed using APEX2 and SAINT programs. Absorption corrections were carried out using SADAB. The structures were solved using SHELXT ${ }^{47}$ and refined using SHELXL-2013 ${ }^{47}$ for full-matrix least-squares refinement that was based on $F^{2}$. For all structures, $\mathrm{H}$ atoms were included in calculated positions and allowed to refine in a ridingmotion approximation with Uiso tied to the carrier atom. All reactions were carried out under a nitrogen atmosphere using Schlenk techniques unless otherwise described. $\mathrm{LiAlH}_{4}\left(1.0 \mathrm{M}\right.$ in $\mathrm{Et}_{2} \mathrm{O}$ ), $\mathrm{NaBH}_{4}, 1.0 \mathrm{M}$ solution of $\mathrm{HCl}$ in Et $\mathrm{C}_{2} \mathrm{O}$, anhydrous $\mathrm{CaCl}_{2}$, anhydrous $\mathrm{MgCl}_{2}$ and Wilkinson's catalyst were purchased commercially and used without further purification. Solvents were dried by standard procedures prior to use.

\section{3-(triphenylstannyl)propyl-4-methylbenzenesulfonate 4}

In a $250 \mathrm{~mL}$ round bottom flask, triphenyl(3-propylhydroxy)stannane $(5.46 \mathrm{~g}, 13.4 \mathrm{mmol}$ ) and $p$-toluenesulfonyl chloride

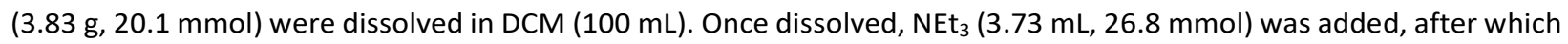
$\mathrm{NMe}_{3} \bullet \mathrm{HCl}(1.28 \mathrm{~g}, 13.4 \mathrm{mmol})$ was added to the solution. The mixture was allowed to react at RT for $2 \mathrm{~h}$. The organic layer was washed with five aliquots of distilled water (DW, $50 \mathrm{~mL}$ ), and the volatile components were removed under reduced pressure. The resulting gel was triturated with $\mathrm{MeOH}(3 \times 20 \mathrm{~mL})$. The residual volatile components were removed under reduced pressure to yield the purified product as a white powder. Yield: $4.50 \mathrm{~g}, 60 \% . \mathbf{M p}=76-77^{\circ} \mathrm{C} .{ }^{1} \mathbf{H}-$ NMR $\left(400 \mathrm{MHz}_{\mathrm{CDCl}}, \delta\right): 7.75\left(\mathrm{~d},{ }^{3} \mathrm{~J}_{1 \mathrm{H}-1 \mathrm{H}}=12 \mathrm{~Hz}, 2 \mathrm{H}, \mathrm{H} 4\right), 7.57-7.44\left(\mathrm{~m}, 3 \mathrm{~J}_{117 / 1195 n-1 H}=48 \mathrm{~Hz}, 6 \mathrm{H}, \mathrm{H} 10\right), 7.39-7.31(\mathrm{~m}, 9 \mathrm{H}$, $\mathrm{H} 11$ \& $\mathrm{H} 12), 7.30\left(\mathrm{~d},{ }^{3} \mathrm{~J}_{1 \mathrm{H}-1 \mathrm{H}}=8 \mathrm{~Hz}, 2 \mathrm{H}, \mathrm{H} 3\right), 4.02(\mathrm{t}, 2 \mathrm{H}, \mathrm{H} 6), 2.44(\mathrm{~s}, 3 \mathrm{H}, \mathrm{H} 1), 2.10-1.94(\mathrm{~m}, 2 \mathrm{H}, \mathrm{H} 7), 1.49-1.31(\mathrm{~m}, 2 \mathrm{H}, \mathrm{H} 8)$ ppm; ${ }^{13} \mathrm{C}\left\{{ }^{1} \mathrm{H}\right\}-\mathrm{NMR}\left(100 \mathrm{MHz}, \mathrm{CDCl}_{3}, \delta\right): 144.94$ (C5), 138.28 (C9), 137.28 (C10), 113.54 (C2) 130.13 (C4) 129.41 (C12), 128.95 (C11), 128.21 (C3), 73.34 (C6), 26.42 (C7), 21.96 (C1). 6.19. (C8) ppm; ${ }^{119}$ Sn-NMR (149 MHz, CDCl,$\left.\delta\right):-99.58$ ppm. The NMR spectra obtained agreed with previously reported literature. ${ }^{15}$

\section{(3-([1,1'-biphenyl]-4-yloxy)propyl)triphenylstannane 11}

Method A: In a $50 \mathrm{~mL}$ round bottom flask containing $25 \mathrm{~mL}$ of acetone was added compound 4 (0.50 g, $0.888 \mathrm{mmol}$ ), $\mathrm{K}_{2} \mathrm{CO}_{3}(0.16 \mathrm{~g}, 1.11 \mathrm{mmol})$ and 4-phenylphenol $(0.15 \mathrm{~g}, 0.888 \mathrm{mmol})$. The reaction was heated $\left(65^{\circ} \mathrm{C}\right)$ to reflux with stirring for $72 \mathrm{~h}$ where a cloudy white solution was observed to form. Upon cooling, the acetone was removed in vacuo and redissolved with DCM $(20 \mathrm{~mL})$, filtered and washed with distilled $\mathrm{H}_{2} \mathrm{O}(3 \times 20 \mathrm{~mL})$. The organic phase was dried with $\mathrm{MgSO}_{4}$, filtered and brought to dryness on a rotovap. The crude product was washed with $\mathrm{MeOH}(3 \times 20 \mathrm{~mL})$ to afford a white coloured powder of $\mathbf{1 1}$. The NMR data was consistent with the previously reported literature. ${ }^{26}$ Yield: $0.40 \mathrm{~g}$ (40\%).

Method B. In a $100 \mathrm{~mL}$ round bottom flask, compound 4 (0.50 g, $0.89 \mathrm{mmol}), \mathrm{K}_{2} \mathrm{CO}_{3}(0.16 \mathrm{~g}, 1.11 \mathrm{mmol})$ and $4-$ phenylphenol $(0.19 \mathrm{~g}, 1.11 \mathrm{mmol})$ were dissolved in ACN. The reaction was allowed to reflux for $72 \mathrm{~h}$, after which the volatile components were removed under reduced pressure. The resulting product was redissolved in DCM and washed with 3 aliquots $(50 \mathrm{~mL})$ of a $5 \%$ aq. $\mathrm{Na}_{2} \mathrm{CO}_{3}$ solution. The organic phase was dried with anhydrous $\mathrm{MgSO}_{4}$ and filtered, and the volatile components removed under vacuum to afford an off-white gel. The crude product was tritrated with 
$\mathrm{MeOH}(3 \times 20 \mathrm{~mL})$ to yield the pure product 11 as a white powder. Yield: $0.49 \mathrm{~g}, 98 \%$. The NMR spectrum obtained agreed with previously reported data. ${ }^{26}$

${ }^{1} \mathrm{H}-N M R\left(400 \mathrm{MHz} \mathrm{CDCl}_{3}, \delta\right):$ 7.63-7.54 (m, 6H, H13), 7.54-7.46 (m, 4H, H2 \& H3), 7.44-7.40 (m, 2H, H6), 7.38-7.37 (m, $9 H, H 14$ \& H15), 7.32-7.29 (m, 1H, H1), 6.86-6.84 (d, 3J $\left.\mathrm{J}_{1 \mathrm{H}-1 \mathrm{H}}=8 \mathrm{~Hz}, 2 \mathrm{H}, \mathrm{H7}\right) 4.00(\mathrm{t}, 2 \mathrm{H}, \mathrm{H9}), 2.24-2.23(\mathrm{~m}, 2 \mathrm{H}, \mathrm{H} 10), 1.67-$ $1.63(\mathrm{~m}, 2 \mathrm{H}, \mathrm{H} 11) \mathrm{ppm} .{ }^{119} \mathrm{Sn}\left\{{ }^{1} \mathrm{H}\right\}-\mathrm{NMR}\left(149 \mathrm{MHz}, \mathrm{CDCl}_{3}, \delta\right):-99.42 \mathrm{ppm}$.

\section{3-(methoxypropyl)triphenylstannane 12}

In a $100 \mathrm{~mL}$ round bottom flask, $4(0.50 \mathrm{~g}, 0.91 \mathrm{mmol})$ and $25 \% \mathrm{w} / \mathrm{v} \mathrm{NaOMe} / \mathrm{MeOH}(0.70 \mathrm{~mL}, 2.64 \mathrm{mmol})$ were combined and dissolved in $50 \mathrm{~mL} \mathrm{ACN}$. The solution was heated under reflux for $24 \mathrm{~h}$, after which the ACN was removed under reduced pressure. The product was then redissolved in $\mathrm{DCM}$ and washed with aliquots $(3 \times 50 \mathrm{~mL})$ of a $5 \%$ aq. $\mathrm{Na}_{2} \mathrm{CO}_{3}$ solution. The organic later was dried with anhydrous $\mathrm{MgSO}_{4}$, filtered, and the $\mathrm{DCM}$ removed under reduced pressure. The resulting solution was recrystallized in heptane to yield the purified product as white crystals. Yield: $0.34 \mathrm{~g}, 89 \%$. ${ }^{1} \mathrm{H}-\mathrm{NMR}\left(400 \mathrm{MHz}_{\mathrm{CDCl}}, \delta\right): 7.63-7.49\left(\mathrm{~m},{ }^{3} \mathrm{~J}_{117 / 119 S n-1 \mathrm{H}}=52 \mathrm{~Hz}, 6 \mathrm{H}, \mathrm{H6}\right), 7.38-7.36(\mathrm{~m}, 9 \mathrm{H}, \mathrm{H7} \& \mathrm{H} 8), 3.38(\mathrm{t}, 2 \mathrm{H}, \mathrm{H} 2)$, $3.16(\mathrm{~s}, 3 \mathrm{H}, \mathrm{H} 1), 2.04-1.97\left(\mathrm{~m},{ }^{3} J_{117 / 119 S n-1 H}=64 \mathrm{~Hz}, 2 \mathrm{H}, \mathrm{H3}\right), 1.55-1.51\left(\mathrm{~m},{ }^{2} J_{117 / 119 S n-1 H}=56 \mathrm{~Hz}, 2 \mathrm{H}, \mathrm{H} 4\right) \mathrm{ppm} ;{ }^{13} \mathrm{C}\left\{{ }^{1} \mathrm{H}\right\}-\mathrm{NMR}$ (100 MHz, CDCl,$\delta$ ): 139.40 (C5), 137.16 (C6), 128.87 (C8), 128.54 (C7), 75.37 (C2), 58.47 (C1), 26.61 (C3), 7.47 (C4) ppm; ${ }^{119} \mathrm{Sn}\left\{{ }^{1} \mathrm{H}\right\}-\mathrm{NMR}\left(149 \mathrm{MHz}, \mathrm{CDCl}_{3}, \delta\right):-100.00$ ppm. HRMS: Calc: 443.0768 , Found: $443.0729 \mathrm{~m} / \mathrm{z}(\mathrm{M}+\mathrm{Na})^{+}$.

\section{(3-(triphenylstannyl)propyl) ethanethioate 13}

In a $100 \mathrm{~mL}$ round bottom flask, $4(4.79 \mathrm{~g}, 8.50 \mathrm{mmol}), \mathrm{K}_{2} \mathrm{CO}_{3}(1.47 \mathrm{~g}, 10.63 \mathrm{mmol})$ and thioacetic acid $(0.60 \mathrm{~mL}, 8.50$ $\mathrm{mmol}$ ) were combined and dissolved in ACN. The mixture was allowed to stir at $26^{\circ} \mathrm{C}$ for $48 \mathrm{~h}$ after which the solvent was removed under reduced pressure. The product was redissolved in DCM and washed with a $5 \%$ aq. $\mathrm{Na}_{2} \mathrm{CO}_{3}$ solution $(3 \times 75 \mathrm{~mL})$. The $\mathrm{DCM}$ was dried using anhydrous $\mathrm{MgSO}_{4}$ and filtered. The solvent was removed under reduced pressure affording the clean product 13, as a light brown oil. Yield: $2.77 \mathrm{~g}, 70 \% .{ }^{1} \mathbf{H}-\mathbf{N M R}\left(400 \mathrm{MHz}, \mathrm{CDCl}_{3}, \delta\right): 7.67-7.54(\mathrm{~m}, 6 \mathrm{H}$,

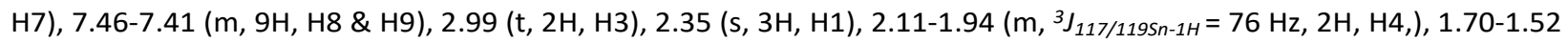
$\left(\mathrm{m},{ }^{2} J_{117 / 119 S n-1 H}=76 \mathrm{~Hz}, 2 \mathrm{H}, \mathrm{H5}\right)$ ppm; ${ }^{13} \mathrm{C}\left\{{ }^{1} \mathrm{H}\right\}-\mathbf{N M R}\left(100 \mathrm{MHz}, \mathrm{CDCl}_{3}, \delta\right): 194.58$ (C2), 137.31 (C6). 135.93 (C7), 127.91 (C9), 127.50 (C8), 31.93 (C3), 29.57 (C1), 25.85 (C4), 8.96 (C5) ppm; ${ }^{119}$ Sn\{ $\left.{ }^{1} \mathbf{H}\right\}-\mathbf{N M R}\left(149 \mathrm{MHz}, \mathrm{CDCl}_{3}, \delta\right):-101.35$ ppm. HRMS: Calc: 483.0488 , Found: $485.0452 \mathrm{~m} / \mathrm{z}(\mathrm{M}+\mathrm{Na})^{+}$.

\section{Chloro(3-methoxypropyl)diphenylstannane 14}

In a $100 \mathrm{~mL}$ round bottom flask, $12(0.32 \mathrm{~g}, 0.76 \mathrm{mmol})$ was dissolved in $\mathrm{C}_{6} \mathrm{H}_{6}(50 \mathrm{~mL})$. An ethereal solution of $1.0 \mathrm{M} \mathrm{HCl}$ in $\mathrm{Et}_{2} \mathrm{O}(0.76 \mathrm{~mL}, 0.76 \mathrm{mmol})$ was added to the stirring solution, and the mixture was allowed to react at RT for $1 \mathrm{~h}$. The volatile components were removed under reduced pressure and the resulting product was recrystallized in heptane to

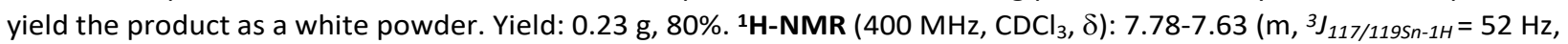
$4 \mathrm{H}, \mathrm{H} 6), 7.45-7.36(\mathrm{~m}, 6 \mathrm{H}, \mathrm{H7} \& \mathrm{H} 8), 3.52(\mathrm{t}, 2 \mathrm{H}, \mathrm{H} 2), 2.95(\mathrm{~s}, 3 \mathrm{H}, \mathrm{H} 1), 2.17-2.11\left(\mathrm{~m}, 3 \mathrm{~J}_{117 / 1195 n-1 H}=56 \mathrm{~Hz}, 2 \mathrm{H}, \mathrm{H} 3\right), 1.80-$ $1.76\left(\mathrm{~m},{ }^{3} \mathrm{~J}_{117 / 119 S n-1 \mathrm{H}}=84 \mathrm{~Hz}, 2 \mathrm{H}, \mathrm{H} 4\right) \mathrm{ppm} ;{ }^{13} \mathrm{C}\left\{{ }^{1} \mathrm{H}\right\}-N M R\left(100 \mathrm{MHz}, \mathrm{CDCl}_{3}, \delta\right): 140.93$ (C5), 136.18 (C6) 129.76 (C8), 128.98 (C7), 73.68 (C2), 58.87 (C1), 25.97 (C3), 15.28 (C4) ppm; ${ }^{119}{ }^{19 n}\left\{{ }^{1} \mathrm{H}\right\}-N M R\left(149 \mathrm{MHz}, \mathrm{CDCl}_{3}, \delta\right):-80.39$ ppm. HRMSDART $\mathrm{m} / \mathrm{z}:\left[\mathrm{M}+\mathrm{NH}_{4}\right]^{+}$Calculated 400.0483 , Found 400.0481.

\section{S-(3-(chloro(diphenylstannyl)propyl) ethanethioate 15}

In a $100 \mathrm{~mL}$ round bottom flask, $13(0.11 \mathrm{~g}, 0.24 \mathrm{mmol})$ was dissolved in $\mathrm{C}_{6} \mathrm{H}_{6}(50 \mathrm{~mL})$. An ethereal solution of $1.0 \mathrm{M} \mathrm{HCl}$ in $\mathrm{Et}_{2} \mathrm{O}(0.24 \mathrm{~mL}, 0.24 \mathrm{mmol})$ was added to the solution, and the mixture was allowed to react at $\mathrm{RT}$ for $1 \mathrm{~h}$. The $\mathrm{C}_{6} \mathrm{H}_{6}$ was then removed under reduced pressure to afford a yellow-brown oil of 15. Yield: $0.10 \mathrm{~g}, 99 \% .{ }^{1} \mathbf{H}-\mathbf{N M R}(400 \mathrm{MHz}$, $\left.\mathrm{CDCl}_{3}, \delta\right): 7.77-7.46(\mathrm{~m}, 4 \mathrm{H}, \mathrm{H} 7), 7.53-7.45\left(\mathrm{~m}, 6 \mathrm{H}, \mathrm{H} 8\right.$ \& H9), 2.97 (t, 2H, H3), $2.27(\mathrm{~s}, 3 \mathrm{H}, \mathrm{H} 1), 2.19-2.12\left(\mathrm{~m},{ }^{3} J_{117 / 1195 n-1 H}\right.$ $=68 \mathrm{~Hz}, 2 \mathrm{H}, \mathrm{H} 4), 1.91-1.72 \mathrm{ppm}\left(\mathrm{m},{ }^{2} J_{117 / 1195 n-1 H}=76 \mathrm{~Hz}, 2 \mathrm{H}, \mathrm{H} 5\right)$ ppm; ${ }^{13} \mathrm{C}\left\{{ }^{1} \mathrm{H}\right\}-\mathrm{NMR}(100 \mathrm{MHz}, \mathrm{CDCl}, \delta): 195.21(\mathrm{C} 2)$, 137.82 (C6), 134.85 (C7), 129.12 (C9), 127.96 (C8), 31.06 (C3), 29.59 (C1), 24.82 (C4), 15.91 (C5) ppm; ${ }^{119}$ Sn\{ $\left.{ }^{1} \mathrm{H}\right\}-N M R$ (149 $\left.\mathrm{MHz} \mathrm{CDCl}_{3}, \delta\right):-0.98 \mathrm{ppm}$.

\section{Dichloro((3-phenylstannyl)propyl) methylbenzenesulfonate 16}

In a $100 \mathrm{~mL}$ round bottom flask, 4 (1.13 g, $2.01 \mathrm{mmol})$ was dissolved in $\mathrm{C}_{6} \mathrm{H}_{6}(50 \mathrm{~mL}) .1 \mathrm{M} \mathrm{HCl}$ in Et $\mathrm{O}_{2} \mathrm{O}(2.01 \mathrm{~mL}, 2.01$

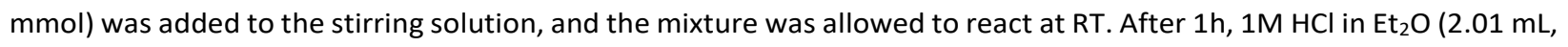
$2.01 \mathrm{mmol}$ ) was added and the reaction was allowed to stir for an additional hour. The volatile components were removed under reduced pressure and the resulting product recrystallized in heptane to yield the purified product as a white powder. Yield: $0.93 \mathrm{~g}, 97 \%$. The NMR spectrum obtained agreed with previously reported data. ${ }^{22}{ }^{1} \mathbf{H}-\mathbf{N M R}(400$ 
$\left.\mathrm{MHz}_{\mathrm{CDCl}}, \delta\right): 7.73\left(\mathrm{~d}, 3^{3} \mathrm{~J}_{1 \mathrm{H}-1 \mathrm{H}}=8 \mathrm{~Hz}, 2 \mathrm{H}, \mathrm{H} 4\right), 7.66-7.64(\mathrm{~m}, 2 \mathrm{H}, \mathrm{H} 10), 7.56-7.47(\mathrm{~m}, 3 \mathrm{H}, \mathrm{H} 11$ \& $\mathrm{H} 12), 7.33\left(\mathrm{~d}, 3_{1 H-1 H}=8\right.$ $\mathrm{Hz}, 2 \mathrm{H}, \mathrm{H3}), 4.14\left(\mathrm{t},{ }^{3} \mathrm{~J}_{1 \mathrm{H}-1 \mathrm{H}}=6 \mathrm{~Hz}, 2 \mathrm{H}, \mathrm{H6}\right), 2.44(\mathrm{~s}, 3 \mathrm{H}, \mathrm{H} 1), 2.28-2.21\left(\mathrm{~m}, 3^{3} \mathrm{~J}_{117 / 1195 n-1 \mathrm{H}}=64 \mathrm{~Hz}, 2 \mathrm{H}, \mathrm{H7}\right), 2.05-1.88(\mathrm{~m}$, $\left.{ }^{2} J_{117 / 119 S n-1 H}=64 \mathrm{~Hz}, 2 \mathrm{H}, \mathrm{H} 8\right) \mathrm{ppm} ;{ }^{13} \mathrm{C}\left\{{ }^{1} \mathrm{H}\right\}-\mathbf{N M R}\left(100 \mathrm{MHz}, \mathrm{CDCl}_{3}, \delta\right): 145.50$ (C5), 138.91 (C9), 135.15 (C10), 132.79 (C2), 131.92 (C12), 130.29 (C3), 129.86 (C11), 128.33 (C4), 71.37 (C6), 24.82 (C7), 22.00 (C1), 21.20 (C8) ppm; ${ }^{119}$ Sn-NMR (149 $\left.\mathrm{MHz}, \mathrm{CDCl}_{3}, \delta\right): 30.79 \mathrm{ppm}$.

\section{Dichloro(3-methoxypropyl)diphenylstannane 18}

In a dry $50 \mathrm{~mL}$ Schlenk flask, compound 14 (0.10 g, $0.262 \mathrm{mmol})$ in $\mathrm{C}_{6} \mathrm{H}_{6}(30 \mathrm{~mL})$ was added. Then an ethereal solution of $1.0 \mathrm{M} \mathrm{HCl}$ in $\mathrm{Et}_{2} \mathrm{O}(1.76 \mathrm{~mL}, 1.28 \mathrm{~g}, 1.75 \mathrm{mmol})$ was added by syringe and stirred for $1 \mathrm{~h}$ at $0 \circ \mathrm{C}$. The residual solvent was removed in vacuo to obtain a white colored solid of 18 in near quantitative yield. Yield: $0.58 \mathrm{~g}(98 \%)$. $\mathbf{M p}=99-100$ ${ }^{\circ} \mathrm{C} .{ }^{1} \mathrm{H}-\mathrm{NMR}\left(400 \mathrm{MHz}, \mathrm{CDCl}_{3}, \delta\right): 7.86-7.65\left(\mathrm{~m},{ }^{3} \mathrm{~J}_{117 / 1195 n-1 \mathrm{H}}=80 \mathrm{~Hz}, 2 \mathrm{H}, \mathrm{H6}\right), 7.51-7.43(\mathrm{~m}, 3 \mathrm{H}, \mathrm{H} 7$ \& H8), $3.62(\mathrm{t}, 2 \mathrm{H}, \mathrm{H} 2)$, $3.30(\mathrm{~s}, 3 \mathrm{H}, \mathrm{H} 1), 2.22-2.17\left(\mathrm{~m},{ }^{3} J_{117 / 119 S n-1 H}=24 \mathrm{~Hz}, 2 \mathrm{H}, \mathrm{H} 3\right), 2.10-1.85\left(\mathrm{~m},{ }^{2} \mathrm{~J}_{117 / 1195 n-1 \mathrm{H}}=88 \mathrm{~Hz}, 2 \mathrm{H}, \mathrm{H} 4\right) \mathrm{ppm} ;{ }^{13} \mathrm{C}\left\{{ }^{1} \mathrm{H}\right\}-\mathrm{NMR}$ (100 MHz, CDCl $3, \delta$ ): 141.36 (C5), 135.30 (C6), 131.07 (C8), 129.49 (C7), 72.14 (C2), 59.00 (C1), 25.38 (C3), 22.59 (C4) ppm; ${ }^{119} \mathrm{Sn}\left\{{ }^{1} \mathrm{H}\right\}-\mathrm{NMR}\left(149 \mathrm{MHz}, \mathrm{CDCl}_{3}, \delta\right):-83.53 \mathrm{ppm}$. HRMS-DART m/z: $\left[\mathrm{M}+\mathrm{NH}_{4}\right]^{+}$Calculated 357.9773, Found 357.9771 .

\section{S-(3-(dichloro(phenyl)stannyl)propyl) ethanethioate 19}

In a $100 \mathrm{~mL}$ round bottom flask, $15(0.10 \mathrm{~g}, 0.23 \mathrm{mmol})$ was dissolved in $\mathrm{C}_{6} \mathrm{H}_{6}(50 \mathrm{~mL})$. An ethereal solution of $1 \mathrm{M} \mathrm{HCl}$ in $\mathrm{Et}_{2} \mathrm{O}(0.23 \mathrm{~mL}, 0.23 \mathrm{mmol})$ was added to the solution, and the mixture was allowed to react at RT for $1 \mathrm{~h}$, after which the solvent was removed under reduced pressure to yield an on-off white powder. Yield: $0.080 \mathrm{~g}, 89 \% . \mathbf{M p}=85^{\circ} \mathrm{C}$. ${ }^{1} \mathbf{H}-$ NMR (400 MHz, $\left.\mathrm{CDCl}_{3}, \delta\right): 7.84-7.63(\mathrm{~m}, 2 \mathrm{H}, \mathrm{H} 7), 7.54-7.43(\mathrm{~m}, 3 \mathrm{H}, \mathrm{H} 8$ \& H9), $3.03(\mathrm{t}, 2 \mathrm{H}, \mathrm{H} 3), 2.27-2.20(\mathrm{~m}, 2 \mathrm{H}, \mathrm{H} 4)$, $2.24(\mathrm{~s}, 3 \mathrm{H}, \mathrm{H} 1), 2.08-1.90\left(\mathrm{~m},{ }^{2} J_{117 / 119 S n-1 H}=64 \mathrm{~Hz}, 2 \mathrm{H}, \mathrm{H} 5\right)$ ppm; ${ }^{13} \mathrm{C}\left\{{ }^{1} \mathrm{H}\right\}-\mathrm{NMR}\left(100 \mathrm{MHz}, \mathrm{CDCl}_{3}, \delta\right): 196.24(\mathrm{C} 2), 139.95$ (C6), 134.83 (C7), 131.35 (C8), 129.49 (C9). 31.35 (C3), 30.77 (C1), 25.10 (C4), 25.07 (C5) ppm; ${ }^{119} \mathrm{Sn}\left\{{ }^{1} \mathrm{H}\right\}-\mathrm{NMR}$ (149 MHz, $\mathrm{CDCl}_{3}, \delta$ ): 15.25 ppm. HRMS-DART: $\mathrm{m} / \mathrm{z}$ : [M+H $\left.{ }_{2} \mathrm{O}\right]$ Calculated 401.94927, Found 401.94892.

\section{3-(phenylstannyl)propyl methylbenzenesulfonate 20}

In a $100 \mathrm{~mL}$ Schlenk flask, $16(0.50 \mathrm{~g}, 1.09 \mathrm{mmol})$ was dissolved in dry EtOH (12 mL) and allowed to stir on ice. In a $50 \mathrm{~mL}$ Schlenk flask, $\mathrm{NaBH}_{4}(0.35 \mathrm{~g}, 9.36 \mathrm{mmol})$ was dissolved in dry $\mathrm{EtOH}(6 \mathrm{~mL})$ and allowed to stir on ice. The solution containing $\mathrm{NaBH}_{4}$ was cannula transferred into the flask containing 16 . The mixture was allowed to react at $0{ }^{\circ} \mathrm{C}$ for $1 \mathrm{~h}$, after which the reaction was quenched with degassed water. The product was extracted with hexane, which was then washed once with degassed water $(25 \mathrm{~mL})$. The organic layer was dried with anhydrous $\mathrm{MgSO}_{4}$, filtered and the volatile components were removed under reduced pressure to yield the purified product as an off-white gel. Yield: $0.31 \mathrm{~g}, 69 \%$. The NMR spectrum obtained agreed with previously reported data. ${ }^{22}{ }^{1} \mathbf{H}-\mathbf{N M R}\left(400 \mathrm{MHz}, \mathrm{CDCl}_{3}, \delta\right): 7.74\left(\mathrm{~d},{ }^{3} J_{1 H-1 H}=8\right.$ $\mathrm{Hz}, 2 \mathrm{H}, \mathrm{H} 4), 7.37-7.22\left(\mathrm{~m},{ }^{3} \mathrm{~J}_{117 / 119 S n-1 H}=52 \mathrm{~Hz}, 2 \mathrm{H}, \mathrm{H} 11\right)$ 7.13-7.11 (m, 3H, H9 \& H10), $6.69\left(\mathrm{~d}, 3^{3} \mathrm{~J}_{1 \mathrm{H}-1 \mathrm{H}}=8 \mathrm{~Hz}, 2 \mathrm{H}, \mathrm{H} 3\right), 5.29$ $\left(\mathrm{s},{ }^{1} J_{117 \mathrm{Sn}-1 \mathrm{H}}=1764 \mathrm{~Hz},{ }^{1} J_{119 \mathrm{Sn}-1 \mathrm{H}}=1820 \mathrm{~Hz}, 2 \mathrm{H}, \mathrm{H} 9\right), 3.70(\mathrm{t}, 2 \mathrm{H}, \mathrm{H} 6), 1.83(\mathrm{~s}, 3 \mathrm{H}, \mathrm{H} 1), 1.56-1.34\left(\mathrm{~m},{ }^{3} J_{117 / 119 S n-1 H}=88 \mathrm{~Hz}\right.$, $2 \mathrm{H}, \mathrm{H7}), 0.79-0.61\left(\mathrm{~m},{ }^{3} \mathrm{~J}_{117 / 1195 n-1 H}=60 \mathrm{~Hz}, 2 \mathrm{H}, \mathrm{H} 8\right) \mathrm{ppm} ;{ }^{119} \mathrm{Sn}-\mathbf{N M R}\left(149 \mathrm{MHz}, \mathrm{CDCl}_{3}, \delta\right):-215.26 \mathrm{ppm}$.

\section{(3-methoxypropyl)(phenyl)stannane 22}

In a $100 \mathrm{~mL}$ Schlenk flask, 18 (0.68 g, $1.78 \mathrm{mmol}$ ) was dissolved in $\mathrm{Et}_{2} \mathrm{O}$. A $1 \mathrm{M} \mathrm{LiAlH}_{4}$ in Et $2 \mathrm{O}(1.78 \mathrm{~mL}, 1.78 \mathrm{mmol})$ solution was added to the flask and placed on ice. The solution was allowed to react at $0{ }^{\circ} \mathrm{C}$ for $1 \mathrm{~h}$, after which the reaction was quenched with degassed water. The organic layer was washed one with degassed water $(50 \mathrm{~mL})$ before being dried with anhydrous $\mathrm{MgSO}_{4}$ and filtered. The organic component was removed under reduced pressure to yield the final product as a dull yellow gel. Yield: $0.40 \mathrm{~g}, 83 \% .{ }^{1} \mathrm{H}-\mathrm{NMR}\left(400 \mathrm{MHz}, \mathrm{CDCl}_{3}, \delta\right): 7.57-7.43\left(\mathrm{~m},{ }^{3} \mathrm{~J}_{117 / 1195 n-1 \mathrm{H}}=52 \mathrm{~Hz}, 2 \mathrm{H}, \mathrm{H7}\right), 7.19-$ $7.13\left(\mathrm{~m}, 3 \mathrm{H}, \mathrm{H} 8\right.$ \& H9), $5.56\left(\mathrm{~s},{ }^{1} J_{1175 n-1 H}=1748 \mathrm{~Hz},{ }^{1} J_{1195 n-1 \mathrm{H}}=1828 \mathrm{~Hz}, 2 \mathrm{H}, \mathrm{H} 5\right), 3.08-3.05(\mathrm{t}, 2 \mathrm{H}, \mathrm{H} 2), 3.00(\mathrm{~s}, 3 \mathrm{H}, \mathrm{H} 1)$, $1.85-1.61\left(\mathrm{~m},{ }^{2} J_{117 / 119 S n-1 H}=84 \mathrm{~Hz}, 2 \mathrm{H}, \mathrm{H3}\right), 1.15-0.97\left(\mathrm{~m},{ }^{3} \mathrm{~J}_{117 / 119 S n-1 H}=56 \mathrm{~Hz}, 2 \mathrm{H}, \mathrm{H} 4\right) \mathrm{ppm} ;{ }^{13} \mathrm{C}\left\{{ }^{1} \mathrm{H}\right\}-\mathrm{NMR}\left(100 \mathrm{MHz}, \mathrm{C}_{6} \mathrm{H}_{6}\right.$,

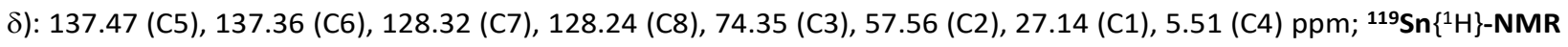
(149 $\left.\mathrm{MHz}_{2} \mathrm{CDCl}_{3}, \delta\right):-215.64 \mathrm{ppm}$. HRMS-DART m/z: [M-H]+ Calculated 271.0139, Found 271.0144.

\section{S-(3-(phenylstannyl)propyl) ethanethioate 23}

In a $100 \mathrm{~mL}$ Schlenk flask, 19 (0.19 g, $0.49 \mathrm{mmol})$ was dissolved in dry EtOH $(12 \mathrm{~mL})$ and allowed to stir on ice. In a 50 $\mathrm{mL}$ Schlenk flask, $\mathrm{NaBH}_{4}(0.17 \mathrm{~g}, 4.45 \mathrm{mmol})$ was dissolved in dry EtOH $(6 \mathrm{~mL})$ and allowed to stir on ice. The solution containing $\mathrm{NaBH}_{4}$ was cannula transferred into the flask containing 19 . The mixture was allowed to react at $0{ }^{\circ} \mathrm{C}$ for $1 \mathrm{~h}$, after which the reaction was quenched with degassed water. The product was extracted with hexane, which was then 
washed once with degassed water $(25 \mathrm{~mL})$. The organic layer was dried with anhydrous $\mathrm{MgSO}_{4}$, filtered and the volatile components were removed under reduced pressure to yield the purified product, 23, as an off-white gel. Yield: $0.09 \mathrm{~g}$, 60\%. ${ }^{1} \mathrm{H}-\mathrm{NMR}\left(400 \mathrm{MHz}, \mathrm{C}_{6} \mathrm{D}_{6}, \delta\right): 7.38-7.37(\mathrm{~m}, 2 \mathrm{H}, \mathrm{H} 8), 7.13-7.12\left(\mathrm{~m}, 3 \mathrm{H}, \mathrm{H} 9\right.$ \& H10), $5.39\left(\mathrm{~s},{ }^{1} J_{1175 n-1 H}=1752 \mathrm{~Hz},{ }^{1} J_{119 S n-}\right.$ $\left.{ }_{1 H}=1832 \mathrm{~Hz}, 2 \mathrm{H}, \mathrm{H} 6\right), 2.70(\mathrm{t}, 2 \mathrm{H}, \mathrm{H} 3), 1.85(\mathrm{~s}, 3 \mathrm{H}, \mathrm{H} 1), 1.69-1.61(\mathrm{~m}, 2 \mathrm{H}, \mathrm{H} 4), 0.94-0.90(\mathrm{~m}, 2 \mathrm{H}, \mathrm{H} 5) \mathrm{ppm} ;{ }^{13} \mathrm{C}\left\{{ }^{1} \mathrm{H}\right\}-\mathrm{NMR}$ (100 MHz, $\left.\mathrm{CDCl}_{3}, \delta\right): 193.02$ (C2), 136.56 (C8), 134.77 (C7) 127.82 (C9), 127.60 (C10), 31.49 (C3), 29.01 (C1), 27.23 (C4), 6.42 (C5) ppm; $\left.{ }^{119} \mathrm{Sn}^{1}{ }^{1} \mathrm{H}\right\}-N M R\left(149 \mathrm{MHz} \mathrm{CDCl}_{3}, \delta\right):-217.63 \mathrm{ppm}$. HRMS-DART m/z: [M-H] ${ }^{+}$Calculated 314.9860, Found 314.9862 .

\section{Synthesis of Substitutionally Labile Polystannane by Dehydrocoupling}

\section{Tosyl homopolystannane 24}

In a foil wrapped $100 \mathrm{~mL}$ Schlenk flask, a solution containing $\mathrm{RhCl}\left(\mathrm{PPh}_{3}\right)_{3}(0.027 \mathrm{~g}, 0.0291 \mathrm{mmol})$ in toluene (10 $\left.\mathrm{mL}\right)$ and stirred at $0{ }^{\circ} \mathrm{C}$ for $15 \mathrm{~min}$ to activate the catalyst. Afterwards, $20(0.30 \mathrm{~g}, 0.730 \mathrm{mmol})$ in toluene $(10 \mathrm{~mL})$ was added dropwise over $10 \mathrm{~min}$ to the catalyst solution and stirred at $0{ }^{\circ} \mathrm{C}$ for $4 \mathrm{~h}$. The mixture was reduced in volume and dissolved again in dry THF. The solution was transferred dropwise to a $100 \mathrm{~mL}$ Schlenk flask containing a stirring solution of cold dry hexane $(65 \mathrm{~mL})$. A yellow orange precipitate was observed immediately and stirred for 5 min before settling. Solvent decanting was done using a Pasteur pipet, after which the residue of $\mathbf{2 4}$ was dried in vacuo to obtain a yellow orange solid. Yield: $0.20 \mathrm{~g}(67 \%) . \mathrm{Mw}=17 \mathrm{kDa} . \oplus=1.26$.

\section{Propylmethoxy Polystannane 25}

In a $100 \mathrm{~mL}$ Al foil wrapped Schlenk flask, Wilkinson's Catalyst ( $0.008 \mathrm{~g}, 0.008 \mathrm{mmol}$ ) was added and dissolved in toluene $(30 \mathrm{~mL})$. The mixture was allowed to stir on ice for $20 \mathrm{~min}$. In a separate $100 \mathrm{~mL}$ Al foil wrapped Schlenk flask 22 (0.12 $\mathrm{g}, 0.44 \mathrm{mmol}$ ) was dissolved in toluene. The solution containing 22 was added to the stirring solution containing Wilkinson's Catalyst dropwise. The mixture was allowed to react at RT for $4 \mathrm{~h}$, after which the toluene was removed under reduced pressure. The crude polymer $\mathbf{2 5}$ was redissolved in minimal THF $(2 \mathrm{~mL})$ and precipitated in a stirring solution of cold hexane $(50 \mathrm{~mL})$. The top layer of hexane was decanted, and the residual solvent removed under reduced pressure to yield 25 as a yellow-orange powder. Yield: $0.070 \mathrm{~g}, 64 \%$.

${ }^{1} \mathrm{H}-\mathrm{NMR}\left(400 \mathrm{MHz} \mathrm{CDCl}_{3}, \mathrm{~d}\right):$ 7.77-7.45 (bm, 2H, H6), 7.07-6.98 (bm, 3H, H7 \& H8), 3.17-2.93 (bm, 5H, H1 \& H2), 1.76-

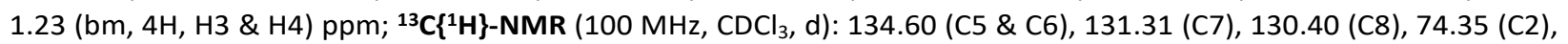
56.72 (C1), 28.90 (C3), 24.45 (C4) ppm; ${ }^{119}$ Sn-NMR (149 MHz, CDCl 3 , d): -237.90 ppm. E. A. Calc. C 44.66, H 5.25, Found. C $35.58, \mathrm{H} 4.57$.

\section{Preparation of a Substituted MeO Polystannane 28}

In a $100 \mathrm{~mL}$ Al foil wrapped Schlenk flask, homopolymer $24(0.45 \mathrm{~g}, 1.10 \mathrm{mmol})$ was added and dissolved in a 10:1 solution of toluene/MeOH $(20 \mathrm{~mL})$. Once dissolved, $25 \% \mathrm{w} / \mathrm{v} \mathrm{NaOMe} / \mathrm{MeOH}(0.23 \mathrm{~mL}, 1.06 \mathrm{mmol})$ was added to the solution. The mixture was allowed to stir at RT for $1 \mathrm{wk}$, after which the solution was filtered, and the volatile components removed. The crude polymer was dissolved in a minimal amount of THF (1-2 $\mathrm{mL}$ ) and precipitated into a stirring solution of cold hexane $(50 \mathrm{~mL})$. The top layer of hexane was decanted, and the residual solvent was removed under reduced pressure to afford 28 as an off-white powder. Yield: $0.170 \mathrm{~g}, 57 \%$.

${ }^{1} \mathrm{H}-\mathrm{NMR}\left(400 \mathrm{MHz}, \mathrm{C}_{6} \mathrm{D}_{6}, \mathrm{~d}\right)$ : 7.82-7.62 (bm, 2H, H6), 7.25-7.18 (bm, 2H, H7), 6.85-6.77 (bm, 1H, H8), 3.26-2.78 (bm, 3H, $\mathrm{H} 1), 2.10-1.16\left(\mathrm{bm}, 6 \mathrm{H}, \mathrm{H} 2, \mathrm{H} 3\right.$ \& H4); ${ }^{119} \mathrm{Sn}-\mathbf{N M R}\left(149 \mathrm{MHz}, \mathrm{C}_{6} \mathrm{D}_{6}, \mathrm{~d}\right):-203.05,-236.67 \mathrm{ppm}$.

\section{Computational Details}

The Gaussian 16 suite of programs was used for all geometric optimizations and frequency calculations (G16 Rev C.01). 48 DFT was implemented with four density functionals (PBE0 "PBE1PBE", M05-2X, B3-PW91, and MN15) supplemented with Grimme's D3 empirical dispersion function and, with the exception of M05-2X, Becke-Johnson damping. ${ }^{30}$ The LANL08d basis set (obtained from the Basis Set Exchange) ${ }^{49}$ was used for Sn, and the 6-31+G(d,p) basis set for all other atoms, as a reasonable compromise between accuracy and computational cost. ${ }^{50,51}$ Tight convergence criteria and superfine integration grids were used for all geometry optimizations, in each case with verification by frequency calculation that a potential energy minimum had been located. Counterpoise corrections in calculations of dimers were applied during geometrical optimizations and frequency calculations. Cartesian coordinates for experimental structures were extracted from crystallographic information files (.cif) with OpenBabelGUI. ${ }^{52}$ Solvation was implemented with the default Gaussian 16 method (the Polarizable Continuum Model using the integral equation formalism variant (IEF- 
PCM). ${ }^{53}$ Conformer fractions for compounds were calculated by determining $q_{i}=\alpha e^{-\Delta \mathrm{G} / R T}$ for each conformer $i$, where $\alpha$ is the total degeneracy of the conformer. Dividing $q_{i}$ by the sum of all $q$ gives the fraction of conformer $i$. The Amsterdam density functional code (ADF/2017.207) ${ }^{54}$ was used to calculate single point energies by the relativistic zeroth-order regular approximation (ZORA) method with optimized TZP basis sets and the PBEO method with $50 \%$ Hartree-Fock exchange. ${ }^{119} \mathrm{Sn}$ chemical shifts were determined with the ADF nmr property module ${ }^{55}$ at the PBE0-50/TZP spin-orbit level. $\mathrm{SnMe}_{4}$ (geometrically optimized as above) was used as the reference to determine relative chemical shifts. Boltzmann-averaged ${ }^{119} \mathrm{Sn}$ chemical shifts were determined by summing the product of the chemical shift and the conformer fraction for each conformer.

\section{Conflicts of interest}

"There are no conflicts to declare".

\section{Acknowledgements}

This work was supported by the NSERC Discovery Grant program. Computational studies (Wylie, Silverthorne) were made possible by the facilities of Compute/Calcul Canada and the Ryerson Analytical Facility.

Supplementary Material

Crystallographic Data was deposited with the following CCDC numbers (\#2102113 12, \#2102119 14, \#2102115 18, and \#2102113 19).

\section{References}

1 A.G. Davies, Organotin Chemistry, Wiley-VCH, Weinheim, 2nd edn., 2004.

2 A. U. Khan and D. A. Foucher, in Main Group Strategies towards Functional Hybrid Materials, eds. T. Baumgartner and F. Jäkle, John Wiley \& Sons, Inc., 2017, pp. 209-236.

3 N. Devylder, M. Hill, K. C. Molloy and G. J. Price, J. Chem. Soc., Chem. Commun., 1996, 711-712.

4 P. R. Deacon, N. Devylder, M. S. Hill, M. F. Mahon, K. C. Molloy and G. J. Price, J. Organomet. Chem., $2003,687,46-56$.

5 D. Miles, T. Burrow, A. Lough and D. Foucher, J. Inorg. Organomet. Polym. Mater., 2010, 20, 544-553.

6 M. Okano, N. Matsumoto, M. Arakawa, T. Tsuruta and H. Hamano, Chem. Commun., 1998, 1799-1800.

7 M. Okano and K. Watanabe, Electrochem. Commun., 2000, 2, 471-474.

8 T. Imori and T. D. Tilley, J. Chem. Soc. Chem. Commun., 1993, 1607-1609.

9 V. Lu and T. D. Tilley, Macromolecules, 1996, 29, 5763-5764.

10 V. Y. Lu and T. D. Tilley, Macromolecules, 2000, 33, 2403-2412.

11 J. T. B. H. Jastrzebski and G. Van Koten, Adv. Organomet. Chem., 1993, 35, 241-294.

A. Růžička, R. Jambor, J. Brus, I. Císařová and J. Holeček, Inorganica Chim. Acta, 2001, 323, 163-170.

I. A. Portnyagin, V. V. Lunin and M. S. Nechaev, J. Organomet. Chem., 2008, 693, 3847-3850.

S. Touqeer, L. Castoldi, T. Langer, W. Holzer and V. Pace, Chem. Commun., 2018, 54, 10112-10115.

J. Pau, A. J. Lough, R. S. Wylie, R. A. Gossage and D. A. Foucher, Chem. Eur. J., 2017, 57, 14367-14374.

K. A. Günay, P. Theato and H.-A. Klok, in Functional Polymers by Post-Polymerization Modification: Concepts,

Guidelines, and Applications, eds. P. Theato and H. Klok, Wylie-VCH, 2013, pp. 1-44.

J. Pau, G. M. D’Amaral, A. J. Lough, R. S. Wylie and D. A. Foucher, Chem. Eur. J., 2018, 24, 18762-18771.

T. Munguia, M. Lo, F. Cervantes-lee, K. H. Pannell, V. Uni and E. Paso, Inorg. Chem., 2007, 46, 1305-1314.

A. Khan, S. Komejan, A. Patel, C. Lombardi, A. J. Lough and D. A. Foucher, J. Organomet. Chem., 2015, 776, $180-191$.

T. Lebl, A. Smicka, J. Brus and C. Bruhn, Eur. J. Inorg. Chem., 2003, 143-148.

A. W. Addison, T. N. Rao, J. Reedijk, J. van Rijn and G. C. Verschoor, J. Chem. Soc., Dalton. Trans., 1984, 1349-1356.

A. Khan, J. Pau, J. Loungxay, T. Magobenny, R. S. Wylie, A. J. Lough and D. Foucher, J. Organomet. Chem., 2019, 900, 120910.

D. N. Bender, A. J. Lough, R. S. Wylie, R. A. Gossage and D. A. Foucher, Inorganics, 2020, 8, 1-22.

S. L. Hinchley, D. A. Wann and D. W. H. Rankin, Int. J. Quantum Chem., 2005, 101, 878-884.

P. D. McCaffrey, R. J. Mawhorter, A. R. Turner, P. T. Brain and D. W. H. Rankin, J. Phys. Chem. A, 2007, 111, 6103-6114.

S. F. Sousa, E. S. Carvalho, D. M. Ferreira, I. S. Tavares, P. A. Fernandes, M. J. Ramos and J. A. N. F. Gomes, J. Comput. 
Chem., 2009, 30, 2752-2763.

J. P. Perdew, in Electronic Structure of Solids '91, eds. P. Ziesche and H. Eschig, Akademie Verlag, Berlin, Germany, 1991, pp. 11-20.

J. P. Perdew, K. Burke and M. Ernzerhof, Phys. Rev. Lett., 1996, 77, 3865-3868.

S. Grimme, S. Ehrlich and L. Goerigk, J. Comput. Chem., 2011, 32, 1456-1465.

Y. Zhao, N. E. Schultz and D. G. Truhlar, J. Chem. Theory Comput., 2006, 2, 364-382.

H. S. Yu, X. He, S. L. Li and D. G. Truhlar, Chem. Sci., 2016, 7, 5032-5051.

H. S. Yu, X. He, S. L. Li and D. G. Truhlar, Chem. Sci., 2016, 7, 6278-6279.

Y. Izato, A. Matsugi, M. Koshi and A. Miyake, Phys. Chem. Chem. Phys., 2019, 21, 18920-18929.

L. B. Krivdin, Russ. Chem. Rev., 2021, 90, 1166-1212.

R. Vivas-Reyes, F. De Proft, M. Biesemans, R. Willem and P. Geerlings, J. Phys. Chem. A, 2002, 106, 2753-2759.

A. Bagno, G. Casella and G. Saielli, J. Chem. Theory Comput., 2006, 2, 37-46.

P. Matczak, MAIN Gr. Met. Chem., 2008, 31, 189-202.

P. Matczak, MAIN Gr. Met. Chem., 2009, 32, 309-320.

C. Zeppek, J. Pichler, A. Torvisco, M. Flock and F. Uhlig, J. Organomet. Chem., 2013, 740, 41-49.

L. Broeckaert, J. Turek, R. Olejnik, A. Ruzicka, M. Biesemans, P. Geerlings, R. Willem and F. De Proft, Organometallics, 2013, 32, 2121-2134.

K. K. Pandey, J. Organomet. Chem., 2016, 815-816, 23-34.

B. Wrackmeyer, Annu. Reports NMR Spectrosc., 1985, 16, 73-186.

B. Wrackmeyer, Annu. Reports NMR Spectrosc., 1999, 38, 203-264.

M. Saito, Y. Okamoto and M. Yoshioka, Appl. Organomet. Chem., 2005, 19, 894-897.

R. N. Kapoor, P. Apodaca, M. Montes, F. D. Gomez and K. H. Pannell, Appl. Organomet. Chem., 2005, 19, 518-522.

G. M. Sheldrick, Acta Cryst., 2015, C71, 3-8.

M. J. Frisch, G. W. Trucks, H. B. Schlegel, G. E. Scuseria, M. A. Robb, J. R. Cheeseman, G. Scalmani, V. Barone, G. A. Petersson, H. Nakatsuji, X. Li, M. Caricato, A. V. Marenich, J. Bloino, B. G. Janesko, R. Gomperts, B. Mennucci, H. P. Hratchian, J. V. Ortiz, A. F. Izmaylov, J. L. Sonnenberg, D. Williams-Young, F. Ding, F. Lipparini, F. Egidi, J. Goings, B. Peng, A. Petrone, T. Henderson, D. Ranasinghe, V. G. Zakrzewski, J. Gao, N. Rega, G. Zheng, W. Liang, M. Hada, M. Ehara, K. Toyota, R. Fukuda, J. Hasegawa, M. Ishida, T. Nakajima, Y. Honda, O. Kitao, H. Nakai, T. Vreven, K. Throssell, J. A. Montgomery, Jr., J. E. Peralta, F. Ogliaro, M. J. Bearpark, J. J. Heyd, E. N. Brothers, K. N. Kudin, V. N. Staroverov, T. A. Keith, R. Kobayashi, J. Normand, K. Raghavachari, A. P. Rendell, J. C. Burant, S. S. Iyengar, J. Tomasi, M. Cossi, J. M. Millam, M. Klene, C. Adamo, R. Cammi, J. W. Ochterski, R. L. Martin, K. Morokuma, O. Farkas, J. B. Foresman and D. J. Fox, Gaussian 16, Rev. C. 01, 2016.

B. P. Pritchard, D. Altarawy, B. Didier, T. D. Gibson and T. L. Windus, J. Chem. Inf. Model., 2019, 59, 4814-4820. S. R. Whittleton, R. J. Boyd and T. B. Grindley, J. Phys. Chem. A, 2006, 110, 5893-5896.

P. Matczak, Comput. Theor. Chem., 2012, 983, 25-30.

N. M. O’Boyle, M. Banck, C. A. James, C. Morley, T. Vandermeersch and G. R. Hutchison, J. Cheminform., DOI:10.1186/1758-2946-3-33.

J. Tomasi, B. Mennucci and R. Cammi, Chem. Rev., 2005, 105, 2999-3093.

G. te Velde, F. M. Bickelhaupt, E. J. Baerends, C. F. Guerra, S. J. A. Van Gisbergen, J. G. Snijders and T. Ziegler, J. Comput. Chem., 2001, 22, 931-967.

G. Schreckenbach and T. Ziegler, J. Phys. Chem., 1995, 99, 606-611. 